\title{
Heart
}

\section{Association of Comorbid Burden with Clinical Outcomes After Transcatheter Aortic Valve Implantation}

\begin{tabular}{|c|c|}
\hline Journal: & Heart \\
\hline Manuscript ID & heartjnl-2018-313356 \\
\hline Article Type: & Original research article \\
\hline Date Submitted by the Author: & 28-Mar-2018 \\
\hline Complete List of Authors: & $\begin{array}{l}\text { Bagur, Rodrigo; London Health Sciences Centre, Western University, } \\
\text { Martin, Glen; University of Manchester Institute of Population Health, Farr } \\
\text { Institute } \\
\text { Nombela-Franco, Luis; Hospital Clinico Universitario San Carlos, } \\
\text { Interventional Cardiology; Institut universitaire de cardiologie et de } \\
\text { pneumologie de Quebec, Cardiology } \\
\text { Doshi, Sagar; University Hospitals Birmingham, Cardiology } \\
\text { George, Sudhakar; Queen Elizabeth Hospital Birmingham } \\
\text { Toggweiler, Stefan; Luzerner Kantonsspital, Cardiology } \\
\text { Sponga, Sandro; University Hospital of Udine, Cardiothoracic Department } \\
\text { Cotton, James; New Cross Hospital, Wolverhampton, Cardiology } \\
\text { Khogali, Saib; Royal Wolverhampton Hospitals NHS Trust } \\
\text { Ratib, Karim; Keele University } \\
\text { Kinnaird, Tim; Keele University, Keele Cardiovascular Research Group; } \\
\text { University Hospital of Wales, Department of Cardiology } \\
\text { Anderson, Richard; University Hospital of Wales, Cardiology } \\
\text { Chu, Michael; London Health Sciences Centre, Western University, } \\
\text { Kiaii, Bob; London Health Sciences Centre, Western University } \\
\text { Biagioni, Corina; Instituto Cardiovascular. Hospital Universitario Clínico San } \\
\text { Carlos } \\
\text { Schofield-Kelly, Lois; New Cross Hospital, Wolverhampton, Cardiology } \\
\text { Loretz, Lucca; Luzerner Kantonsspital, Cardiology } \\
\text { Torracchi, Leonardo; University Hospital of Udine, Cardiothoracic } \\
\text { Department } \\
\text { Sekar, Baskar; University Hospital of Wales, Department of Cardiology } \\
\text { Kwok, Chun Shing; Keele University, Cardiovascular Research Group } \\
\text { Sperrin, Matthew; University of Manchester, Health eResearch Centre, Farr } \\
\text { Institute } \\
\text { Ludman, Peter; Queen Elizabeth Hospital Birmingham, } \\
\text { Mamas, Mamas; Manchester University }\end{array}$ \\
\hline Keywords: & $\begin{array}{l}\text { Transcatheter valve interventions < Interventional cardiology and } \\
\text { endovascular procedures < CARDIAC PROCEDURES AND THERAPY, Aortic } \\
\text { and arterial disease < DISEASES, Aortic stenosis < Valvular Heart Disease } \\
<\text { DISEASES, Epidemiology }<\text { RESEARCH APPROACHES }\end{array}$ \\
\hline Abstract: & $\begin{array}{l}\text { Abstract } \\
\text { Objectives: To investigate the association of the Charlson Comorbidity }\end{array}$ \\
\hline
\end{tabular}


Index (CCI) with clinical outcomes after TAVI.

Background: Patients undergoing transcatheter aortic valve implantation (TAVI) have high comorbid burden, but evidence around the impact of comorbidity on clinical outcomes is limited.

Methods: Data from 1887 patients from the UK, Canada, Spain, Switzerland and Italy were collected between 2007 and 2016. The association of CCI with 30-day mortality, Valve Academic Research Consortium-2 (VARC-2) composite early safety, long-term survival and length of stay (LOS) was calculated using logistic regression and Cox proportional hazard models, as a whole cohort and at a country-level, through a two-stage individual participant data (IPD) random-effect metaanalysis.

Results: Most patients had a $\mathrm{CCI} \geq 3(60 \%)$. A weak correlation was found between the total CCI and four different preoperative risks scores $(\rho=0.16$ to 0.29 ), and approximately $50 \%$ of patients classed as low risk from four risk prediction models still presented with a $\mathrm{CCI} \geq 3$. Per-unit increases in total CCI were not associated with increased odds of 30-day mortality (OR $1.09,95 \%$ CI: $0.96-1.24$ ) or VARC-2 early safety (OR $1.04,95 \%$ CI: $0.96-$ 1.14 ), but was associated with increased hazard of long-term mortality (HR $1.10,95 \% \mathrm{CI}: 1.05-1.16)$. The two-stage IPD meta-analysis indicated that CCI was not associated with LOS (HR 0.97, 95\%CI: 0.93-1.02).

Conclusion: In this multi-centre international study, patients undergoing TAVI had significant comorbid burden. We found a weak correlation between the CCI and well-established preoperative risks scores. The CCI had a moderate association with long-term mortality up-to 5-years post TAVI. 


\section{Association of Comorbid Burden with Clinical Outcomes After Transcatheter Aortic Valve Implantation}

Rodrigo Bagur, ${ }^{1,2,3}$ MD, PhD, FAHA; Glen P. Martin, ${ }^{* 4} \mathrm{PhD}$; Luis Nombela-Franco, ${ }^{5} \mathrm{MD}$, PhD; MBChB, MD, FRCP; Sagar N. Doshi, ${ }^{6}$ MBChB, MD, FRCP; Sudhakar George, ${ }^{6}$ MBChB; Stefan Toggweiler, ${ }^{7}$ MD; Sandro Sponga, MD, ${ }^{8}$ PhD; James Cotton, ${ }^{9}$ MBBS, MD; Saib S. Khogali, ${ }^{9}$ MBChB, FRCP, MD; Karim Ratib, ${ }^{3}$ MBBCh; Tim Kinnaird, ${ }^{10}$ MBBCh; Richard Anderson, ${ }^{10}$ BSc, MBBS, MD, FRCP; Michael W. A. Chu, ${ }^{1}$ MD, FRCSC; Bob Kiaii, ${ }^{1}$ MD, FRCSC; Corina Biagioni, ${ }^{5}$ MD; Lois Schofield-Kelly, ${ }^{9} \mathrm{MBBS}$; Lucca Loretz, ${ }^{7} \mathrm{MD}$; Leonardo Torracchi, ${ }^{8}$ MD; Baskar Sekar, ${ }^{10}$ MD; Chun Shing Kwok, ${ }^{3}$ BSc, MBBS, MSc, MRCP; Matthew Sperrin, ${ }^{4}$ PhD; Peter F. Ludman, ${ }^{6}$ MD, FRCP, FESC; Mamas A. Mamas, ${ }^{3,4}$ MA, DPhil, FRCP

${ }^{1}$ London Health Sciences Centre, London, Ontario, Canada.

${ }^{2}$ Department of Epidemiology and Biostatistics, Schulich School of Medicine \& Dentistry, Western University, London, Ontario, Canada.

${ }^{3}$ Keele Cardiovascular Research Group, Centre for Prognosis Research, Institute for Primary Care and Health Sciences, Keele University, Stoke-on-Trent, United Kingdom.

${ }^{4}$ Farr Institute, Faculty of Biology, Medicine and Health, University of Manchester, Manchester Academic Health Science Centre, Manchester, United Kingdom.

${ }^{5}$ Cardiovascular Institute, Hospital Clínico San Carlos, Madrid, Spain.

${ }^{6}$ Cardiology Department, Queen Elizabeth Hospital, Birmingham, UK.

${ }^{7}$ Heart Center Lucerne, Lucerne, Switzerland.

${ }^{8}$ Cardiothoracic Department, University Hospital of Udine, Udine.

${ }^{9}$ The Heart and Lung Centre, The Royal Wolverhampton Hospitals NHS Trust,

${ }^{10}$ Department of Cardiology, University Hospital of Wales, Cardiff, United Kingdom

Short title: Impact of Charlson Comorbidity Index on TAVI Outcomes

Conflict of Interest: None.

Funding: This work was partially funded by the Medical Research Council through the Health e-Research Centre, University of Manchester [MR/K006665/1]

*These authors contributed equally to the manuscript.

Acknowledgements: The authors would like to thank all members of Heart Teams of each participating centre.

Corresponding Author:

Rodrigo Bagur, MD, PhD, FAHA

University Hospital, London Health Sciences Centre

339 Windermere Road

London, Ontario, N6A 5A5, Canada.

E-mail: rodrigobagur@yahoo.com 


\begin{abstract}
Objectives: To investigate the association of the Charlson Comorbidity Index (CCI) with clinical outcomes after TAVI.

Background: Patients undergoing transcatheter aortic valve implantation (TAVI) have high comorbid burden, but evidence around the impact of comorbidity on clinical outcomes is limited. Methods: Data from 1887 patients from the UK, Canada, Spain, Switzerland and Italy were collected between 2007 and 2016. The association of CCI with 30-day mortality, Valve Academic Research Consortium-2 (VARC-2) composite early safety, long-term survival and length of stay (LOS) was calculated using logistic regression and Cox proportional hazard models, as a whole cohort and at a country-level, through a two-stage individual participant data (IPD) random-effect meta-analysis.
\end{abstract}

Results: Most patients had a $\mathrm{CCI} \geq 3(60 \%)$. A weak correlation was found between the total CCI and four different preoperative risks scores $(\rho=0.16$ to 0.29$)$, and approximately $50 \%$ of patients classed as low risk from four risk prediction models still presented with a $\mathrm{CCI} \geq 3$. Per-unit increases in total CCI were not associated with increased odds of 30-day mortality (OR 1.09, 95\% CI: 0.96-1.24) or VARC-2 early safety (OR 1.04, 95\%CI: $0.96-1.14$ ), but was associated with increased hazard of long-term mortality (HR 1.10, 95\%CI: 1.05-1.16). The two-stage IPD meta-analysis indicated that CCI was not associated with LOS (HR 0.97, 95\%CI: 0.93-1.02).

Conclusion: In this multi-centre international study, patients undergoing TAVI had significant comorbid burden. We found a weak correlation between the CCI and well-established preoperative risks scores. The CCI had a moderate association with long-term mortality up-to 5years post TAVI. 
Keywords: Aortic Stenosis - Transcatheter Aortic Valve Implantation - Comorbidity - Charlson Comorbidity Index - Mortality - Meta-Analysis 


\section{Key message:}

- The majority of patients who underwent TAVI presented with severe comorbid burden as defined by a CCI of $\geq 3$.

- We found a weak correlation between the CCI and well-established preoperative risks scores, and even patients classed as low preoperative risk presented with a $\mathrm{CCI} \geq 3$ in approximately $50 \%$ of the cases.

- The CCI was moderately associated with increased hazard of mortality up-to 5-years post TAVI. 


\section{INTRODUCTION}

In patients with severe symptomatic aortic stenosis (AS) who are considered at high or intermediate operative risk, transcatheter aortic valve implantation (TAVI) has become a standard alternative to surgical aortic valve replacement (SAVR)(1-3).

Validated scoring systems permit the estimation of operative risk according to patients' clinical profile and the type of intervention(4-8). However, these scoring systems are elaborated from large "general" populations and might lack predictive accuracy in specific subgroups, particularly elderly patients with valvular heart disease and multiple comorbid conditions.

The Charlson Comorbidity Index (CCI) is a global measure of comorbidity burden that was developed and validated for estimating prognosis and adverse clinical outcomes in a broad spectrum of patients with multiple coexisting illnesses(9-11). While the Heart Team considers the presence of multiple comorbid conditions of patients during their decision-making processes for TAVI eligibility, the association of comorbid burden with clinical outcomes is mainly limited to single centre studies $(12,13)$ with relatively small sample sizes. Therefore, the aim of this multicentre international study was to report the distribution of comorbidity burden in patients undergoing TAVI and the association with short and long-term clinical outcomes, as well as length of stay (LoS) after TAVI.

\section{METHODS}

\section{Participants}

This analysis included prospective data collected between 2007 and 2016 on all TAVI procedures undertaken across four UK-TAVI centres (Queen Elizabeth Hospital (Birmingham), University Hospital of North Staffordshire (Stoke-On-Trent), University Hospital of Wales (Cardiff) and New Cross Hospital (Wolverhampton)), and four non-UK TAVI centres (University Hospital, London Health Sciences Centre (Ontario, Canada), Cardiovascular 
Institute, Hospital Clínico San Carlos (Madrid, Spain), Heart Center Lucerne (Lucerne, Switzerland) and University Hospital of Udine (Udine, Italy). The UK derived data were extracted from those submitted to the UK TAVI registry $(14,15)$, while the non-UK data were derived from each individual centre's databases. The variables recorded across all centres/countries included patient baseline demographics, pre-procedural risk factors, peri/postprocedural information and outcomes occurring before index hospital discharge. For UK patients, all-cause long-term mortality information was available through linkage with the Office for National Statistics, and for non-UK patients, this information was collected either by last available on-site clinical visit or by telephone contacts. The research ethics boards at the participating sites approved the datasets for the study.

\section{Comorbidity burden measurement}

The CCI was utilized as a measure of comorbid burden(16), and was retrospectively calculated for each patient across all contributing centres. The 19 components of CCI are: previous myocardial infarction, congestive heart failure, peripheral vascular disease, cerebrovascular disease, dementia, chronic obstructive pulmonary disease, connective tissue disease, peptic ulcer disease, mild or severe liver disease, diabetes with or without end-organ damage, moderate-severe chronic kidney disease, hemiplegia, leukemia, lymphoma, any tumour with or without metastases and Acquired Immune Deficiency Syndrome status. Each of the components has an associated weighting, which is summed across the 19 conditions to define the total CCI score; thus, total CCI can range from 0 to 37 points, with higher values indicating increasing comorbid burden. 


\section{Statistical Analysis}

Continuous data were described using the mean and range of values, with group comparisons made using analysis of variance (ANOVA). Likewise, categorical data were presented as raw number of events and corresponding percentages, with comparisons made using the chi-squared test. The primary outcomes in this analysis were 30-day mortality and long-term survival. Secondary outcomes were LoS (defined as the number of days between admission and discharge) and the Valve Academic Research Consortium-2 (VARC-2) composite early safety endpoint (defined as any of the following occurring within 30-days: mortality, stroke, lifethreatening bleed, acute kidney injury, coronary artery obstruction, major vascular complication, and valve-related dysfunction)(17). The impact of comorbidity on each outcome was examined with total CCI modelled as both a continuous variable (i.e. the effect of per-unit increases in total $\mathrm{CCI}$ ), and across strata of $\mathrm{CCI}=0, \mathrm{CCI}=1, \mathrm{CCI}=2$ and $\mathrm{CCI} \geq 3$ (to examine non-linear relationships between total CCI and the outcomes).

Patients with missing information that precluded CCI calculation were excluded from the analysis. Similarly, patients with missing endpoint data were removed from the analysis of that specific endpoint. Missing covariate information was imputed using multiple imputation by chained equations, where we generated ten imputed datasets(18). The imputation models for each covariate included the majority of other baseline covariates, total CCI, each of the considered endpoints, and a random-effect at the country-level(19,20). All subsequent analyses were performed within each imputed dataset, with parameters of interest pooled across imputations using Rubin's rules(18).

Baseline patient risk was summarised with the Logistic EuroSCORE (LES)(5), the EuroSCORE-II (ESII)(21), Society of Thoracic Surgeons (STS) Predicted Risk of Mortality(8), and the TAVI-specific FRANCE-2(22) prediction models. These models were calculated in the 
multiple imputed data and were therefore averaged across imputations. Spearman's rank correlation coefficients were calculated to determine the strength of the correlation between total CCI and each risk model.

Associations between CCI and the binary endpoints (30-day mortality/VARC-2 composite early safety) were examined with logistic regression, with unadjusted, age and sex adjusted, and multivariable adjusted odds ratios (ORs) reported. Similarly, the effect of CCI on long-term survival and LOS was examined non-parametrically using Kaplan-Meier plots, with multivariable adjusted hazard ratios (HRs) estimated with Cox proportional hazards models. Long-term survival was modelled up-to 5 years post-procedural follow-up.

Each of the multivariable adjustments included all baseline/procedural variables that were (a) recorded across all the datasets, and (b) not components of the CCI, or on the causal pathway between CCI and outcome. Specifically, the following variables were included in the multivariable adjustment: age, sex, smoking status, atrial fibrillation, height, weight, Canadian Cardiovascular Society (CCS) class IV, New York Heart Association (NYHA) Functional Classification, coronary artery disease, pulmonary hypertension $(>60 \mathrm{mmHg})$, aortic valve area, left ventricular ejection fraction (LVEF), non-elective procedure indication, and non-transfemoral access route indication.

When analysing the data as a whole cohort, we included a random effect (i.e. random intercept) at a country-level within each of the analysis models, thereby aiming to respect the clustering of the data collection. Similarly, we also performed a two-stage individual participant data (IPD) meta-analysis at a country-level. Here, data from each country were analysed individually, and the results from which were then pooled using a random effects model across countries $(23,24)$. The multiple imputation was incorporated into this process by first applying 


\begin{abstract}
Rubin's rules at the country-level prior to pooling the country-specific estimates using metaanalytical techniques(25).
\end{abstract}

All analyses were performed using $\mathrm{R}$ version 3.4.2(26). Graphical plots were made using the "ggplot2" package(27), the "mice" package was used for the multiple imputation(28), and the meta-analysis was performed with the "metafor" package(29).

\title{
RESULTS
}

Between August 2007 and September 2016, data for $n=1887$ patients were available, comprising 791, 308, 181, 375, 232 patients from the UK, Canada, Italy, Spain and Switzerland, respectively. Patient baseline characteristics as a whole cohort and across strata of CCI are given in Table 1; similarly, Supplementary Table 1 presents baseline characteristics by country. The mean age of patients was 81.6 years with $51.4 \%$ male. Most procedures were undertaken electively and via transfemoral access (83\%). The proportion of patients with atrial fibrillation/flutter $(\mathrm{P}=0.041)$, previous cardiac surgery $(\mathrm{P}=0.020)$, previous balloon-aortic valvuloplasty $(\mathrm{P}=0.003)$, previous percutaneous coronary intervention $(\mathrm{P}<0.001)$, NYHA class III/IV ( $\mathrm{P}=0.002)$, coronary artery disease $(\mathrm{P}<0.001), \mathrm{LVEF}<50 \%(\mathrm{P}<0.001)$ and undergoing nonelective procedures $(\mathrm{P}=0.046)$ varied significantly across strata of total CCI (Table $\mathbf{1})$.

The distribution of total CCI for the whole cohort and by country is given in Figure 1. The median total CCI was 3 (interquartile range: 2-4), with a minimum of 0 and maximum of 11. Across all countries, the majority of patients had a total CCI of 3 or more, with the proportion of patients with $\mathrm{CCI} \geq 3$ ranging from $56 \%$ (UK) to $72 \%$ (Switzerland) (Supplementary Figure 1). The most common cardiovascular comorbidities were previous myocardial infarction (24\%) and congestive heart failure (59\%), while the most common non-cardiovascular comorbidities were chronic kidney disease (50\%) and chronic obstructive pulmonary disease (21\%) (Supplementary

\section{Figure 2).}




\section{CCI and Established Risk Models}

We calculated the LES, ESII, STS and the TAVI-specific FRANCE-2 prediction models for all patients. Unsurprisingly, the proportion of patients with $\mathrm{CCI} \geq 3$ increased across quantiles of the predicted risks from each model (Figure 2). Nevertheless, within the lowest predicted risk quantile, the proportion of patients with a CCI $\geq 3$ was $50.2 \%, 48.5 \%, 46.8 \%$ and $50.4 \%$ for LES, ESII, STS and FRANCE-2, respectively, with a weak Spearman's rank correlation coefficient between the total CCI and predicted LES $(\rho=0.21,95 \% \mathrm{CI}: 0.16-0.25)$, ESII $(\rho=0.21,95 \% \mathrm{CI}$ : 0.16-0.25), STS ( $\rho=0.28,95 \%$ CI: $0.24-0.32)$, and FRANCE-2 $(\rho=0.16,95 \%$ CI: $0.12-0.20)$ score.

\section{0-day and long-term mortality}

Data on 30-day mortality were available in 1644 (87\%) patients, of which, 68 (4.14\%) died within 30 days post TAVI. There was no significant difference in crude 30 -day mortality rates with either per-unit increase in total CCI (OR: 1.11, 95\% CI: 0.98-1.25; Table 2), or across CCI strata $(\mathrm{P}=0.312)$ with 30 -day mortality rates of $1.06 \%, 4.33 \%, 3.29 \%$, and $4.67 \%$ for $\mathrm{CCI}=0$, $\mathrm{CCI}=1, \mathrm{CCI}=2$ and $\mathrm{CCI} \geq 3$, respectively. Similarly, the multivariable adjusted odds for 30 -day mortality were not significantly different for unit increases in total CCI (OR: 1.09, 95\% CI: 0.961.24; Table 2). Across the UK, Canadian, Italian, Spanish and Swiss TAVI centres, the crude proportions of 30-day mortality were 20/567 (3.53\%), 15/308 (4.87\%), 5/162 (3.09\%), 25/375 $(6.67 \%)$, and $3 / 232(1.29 \%)$, respectively $(\mathrm{P}=0.016)$. The two-stage IPD meta-analysis showed that the multivariable adjusted odds of 30-day mortality were significantly higher per unit increase in total CCI for UK patients (OR 1.36, 95\%CI: 1.08-1.71), but no significant differences in 30-day mortality rates were found in patients from other countries, with a pooled OR of 1.12 (95\%CI: 0.88-1.41) (Supplementary Figure 3). 
A total of 1555 patients had data on long-term survival, totalling 3663 person-years of follow-up. The overall six-month, one-year and two-year survival estimates were $91.0 \%, 87.9 \%$ and $79.8 \%$, respectively. Across CCI strata, one-year survival rates were $95.1 \%, 89.3 \%, 90.6 \%$ and $85.9 \%$ for $\mathrm{CCI}=0, \mathrm{CCI}=1, \mathrm{CCI}=2$ and $\mathrm{CCI} \geq 3$, respectively (Figure 3, log-rank $\mathrm{P}<0.001$ ). $\mathrm{A}$ univariable Cox proportional hazards model indicated that the hazard of mortality was significantly higher for unit increases in total CCI (HR 1.11, 95\%CI 1.06-1.16; Table 2). The hazards of mortality remained significantly higher for unit increases in total CCI after adjusting for age and sex (HR 1.11, 95\%CI: 1.06-1.17), and after multivariable adjustment (HR 1.10, 95\%CI: 1.05-1.16). Similarly, long-term survival differed significantly across strata of total CCI with a multivariable adjusted HR of $1.73(95 \% \mathrm{CI}$ : $1.01-2.94)$ for patients with $\mathrm{CCI}=2$ and 2.18 (95\%CI: 1.36-3.61) for those with $\mathrm{CCI} \geq 3$ as compared with those with a $\mathrm{CCI}=0$ (Table 3). The two-stage IPD meta-analysis on hazards for long-term mortality across each participating country resulted in a pooled HR (multivariable adjusted) of 1.13 (95\%CI: $0.98-1.30)$ per unit increases in total CCI (Figure 4).

\section{Length of Stay}

Across the whole cohort, 1820 (96\%) patients had information on their LoS, with a median LoS of 7 days (interquartile range 5-13 days). Unit increases in total CCI were not associated with longer LoS after multivariable adjustment (HR: 1.00, 95\%CI: 0.97-1.02; Table 2). Similar findings were observed within the two-stage IPD meta-analysis with a combined meta-analysis HR of 0.97 (95\%CI: 0.93-1.02; Figure 4).

Analyses for non-linear relationships between CCI and LoS indicated that the multivariable adjusted HRs for a shorter LoS were 1.31 (95\%CI: 1.02, 1.68), 1.41 (95\%CI: 1.11-1.79) and 1.27 (95\%CI: 1.02-1.59) for patients with $\mathrm{CCI}=1, \mathrm{CCI}=2$ and $\mathrm{CCI} \geq 3$, respectively, as compared to 
those with $\mathrm{CCI}=0$ (Table 3). Comparable results were observed when we modelled the (multivariable adjusted) HR for a shorter LoS as a smooth function of total CCI (Figure 5).

The two-stage IPD meta-analysis for LoS, indicated that UK patients with at least 1 comorbid condition (i.e. CCI $>0$ ) had a significantly shorter LoS compared with UK patients with a $\mathrm{CCI}=0$ (Supplementary Figure 4). However, the pooled IPD meta-analysis results showed no significant difference in LoS across strata of total CCI, with pooled HRs of 0.89 (95\%CI: $0.44-$ 1.80), 1.07 (95\%CI: 0.66-1.73) and 0.92 (95\%CI: 0.54-1.54), for $\mathrm{CCI}=1, \mathrm{CCI}=2, \mathrm{CCI} \geq 3$, respectively, compared with $\mathrm{CCI}=0$ (Supplementary Figure 4).

\section{VARC-2 Composite Early Safety}

A total of 745 patients were removed due to missing data on the VARC-2 composite early safety outcome (i.e. patients who were missing components of the composite outcome). Hence, $1142(60.5 \%)$ patients had information on the VARC-2 composite early safety outcome, of which, the event rate was $18.6 \%$. Across strata of CCI, the event rate was 13/69 (18.8\%), 37/201 $(18.4 \%), 26 / 207(12.6 \%)$ and $136 / 665(20.5 \%)$ for $\mathrm{CCI}=0-\mathrm{CCI}=1-\mathrm{CCI}=2$ and $\mathrm{CCI} \geq 3$, respectively $(\mathrm{P}=0.089)$. After multivariable adjustment, the odds of the VARC-2 composite early safety outcome were not significantly different with per-unit increases in total CCI (Table 2) or across strata of total CCI (Table 3).

\section{DISCUSSION}

In this multi-centre international study, the majority of patients who underwent TAVI presented with severe comorbid burden as defined by a CCI of $\geq 3$. We found a weak correlation between the CCI and well-established preoperative risks scores, and even patients classed as low preoperative risk presented with a $\mathrm{CCI} \geq 3$ in approximately $50 \%$ of the cases. While UK patients 
with a CCI between 1 and 3 had shorter LoS, this finding was not observed within the other nonUK centres. The CCI was associated with increased hazard of mortality up-to 5-years post TAVI.

The CCI is a validated tool to assess comorbidity burden and has been shown to be a predictor of outcome in patients with aortic stenosis(12,13,30,31). However, we may have to consider selection bias since TAVI candidates with a $\mathrm{CCI}=0$ are unlikely to be truly "without comorbidity" and may merely have prevalent comorbid conditions not captured by the CCI. Explicitly, it is likely that patients undergoing TAVI presenting a $\mathrm{CCI}=0$ are more comorbid as compared to those in the general population by virtue of the fact that they are considered not suitable for SAVR. Some of the few exemptions to this might be old patients (i.e. $>85$ years), who, solely because of their age, will benefit from a TAVI procedure rather than SAVR(3,32), regardless if they are considered low surgical risk. Therefore, the cohort of patients with a CCI=0 are likely to represent a high-risk cohort by virtue of other comorbid conditions not captured by CCI or frailty.

\section{Pre-operative risk assessment}

The utility of the STS score and the logistic EuroSCORE on patients being evaluated for TAVI is limited(33). Indeed, the poor performance of these scores are due to the fact that they were derived for predicting surgical outcomes and are not calibrated to perform in TAVI procedures in which patients are excluded from SAVR by virtue of certain comorbidities, such as porcelain aorta, chest radiation/hostile chest, cancer, immunodeficiency, liver disease/cirrhosis, and frailty, that, among others, are not computed into the risk models. A such, this may translate into an incorrect decision-making processes, but also, it might artificially exaggerate the positive results obtained with either surgical or transcatheter procedures(34). Our results show a weak correlation between the CCI and STS score, LES, ESII and FRANCE-2 scores. Importantly, even those patients classed as low preoperative risk were still relatively comorbid as defined by a 
$\mathrm{CCI} \geq 3$ in approximately $50 \%$ of the patients. These results suggest that the risk models do not capture several aspects of preoperative risk.

\section{Comorbidity burden and mortality}

Our results indicate that comorbidity burden assessed by the CCI was not associated with significantly higher odds of 30-day mortality, yet, it was in the long-term. These results are in line with previous reports $(12,13,35)$. A potential explanation is that procedural-related variables have a greater impact on in-hospital and 30-day mortality $(35,36)$, but (other than stroke within 30 days) procedural variables do not impact long-term survival following TAVI (36). These findings support the theory that comorbid conditions have a greater impact on long-term mortality than the index TAVI procedure. Indeed, it is known that moderate to high-risk patients, the majority die from non-cardiac conditions $(13,35,37,38)$. The current analysis suggests that CCI score moderately correlated with survival up-to 5-year post procedure across multiple countries/centres, each with different practices and valve types. Hence, further supporting the notion that if the patient gets through the procedure, then again, mortality is driven by the common comorbid states that general ageing features ensure take over. Therefore, the use of CCI may potentially serve as a measure to estimate long-term mortality as compared to standard risk assessment.

\section{Comorbidity Burden and Length of Stay}

The results from this analysis indicate that CCI was generally not associated with LoS. UK patients with a higher total CCI were significantly more likely to be discharged earlier than those with a $\mathrm{CCI}=0$, but this was not observed across all countries. One needs to interpret these findings with caution given that $\operatorname{LoS}$ is driven by several clinical but also non-clinical factors such as home circumstances and country or centre-specific practices for discharge. Moreover, certain centers with a predominant use of self-expanding TAVI devices, may delay discharge due 
to perceived need for latter permanent pacemaker implantation. Additionally, the time period for the analysis (2007-2016) covers temporal changes to TAVI practice such as the introduction of conscious sedation and new devices technology, thus, potentially weakening comorbidity and LoS associations; future analyses on contemporary cohorts of TAVI patients could investigate this further.

\section{Limitations}

Several limitations need to be considered. Firstly, although our results were obtained from prospectively gathered datasets, the retrospective nature of the analysis are exposed to potential (unmeasured) confounders. Therefore, we cannot interpret the results as causal, but rather they represent associations between CCI and the investigated outcomes. Secondly, in most centers we only had data on CCI as a quantification of comorbid burden. Although this is a widely used and validated measure of estimating prognosis and adverse clinical outcomes, the findings may differ if other comorbidity scales were used. Finally, as discussed above, selection bias needs to be considered in this context, since TAVI patients with a $\mathrm{CCI}=0$ are unlikely to be representative of those in the general population with $\mathrm{CCI}=0$.

\section{Conclusion}

In this multi-centre, international study, the majority of patients who underwent TAVI presented with 3 or more comorbid conditions as assessed by the CCI. We found a weak correlation between the CCI and well-established preoperative risks scores and, even those patients classed as low preoperative risk presented with a $\mathrm{CCI} \geq 3$ in about $50 \%$ of the patients. While the 30-day mortality rates were significantly higher per unit increase in total CCI for UK patients, no statistically significant differences were found in patients from other countries. The CCI was associated with increased hazard of mortality up-to 5-years post TAVI, suggesting that 
$\mathrm{CCI}$ is a potentially useful measure to assess long-term outcomes compared with standard risks assessment. 


\section{References}

1. Leon MB, Smith CR, Mack MJ et al. Transcatheter or Surgical Aortic-Valve Replacement in Intermediate-Risk Patients. N Engl J Med 2016;374:1609-20.

2. Reardon MJ, Van Mieghem NM, Popma JJ et al. Surgical or Transcatheter Aortic-Valve Replacement in Intermediate-Risk Patients. N Engl J Med 2017;376:1321-1331.

3. Vandvik PO, Otto CM, Siemieniuk RA et al. Transcatheter or surgical aortic valve replacement for patients with severe, symptomatic, aortic stenosis at low to intermediate surgical risk: a clinical practice guideline. BMJ 2016;354:i5085.

4. Geissler HJ, Holzl P, Marohl S et al. Risk stratification in heart surgery: comparison of six score systems. Eur J Cardiothorac Surg 2000;17:400-6.

5. Roques F, Michel P, Goldstone AR, Nashef SA. The logistic EuroSCORE. Eur Heart J $2003 ; 24: 881-2$.

6. Ambler G, Omar RZ, Royston P, Kinsman R, Keogh BE, Taylor KM. Generic, simple risk stratification model for heart valve surgery. Circulation 2005;112:224-31.

7. Ranucci M, Castelvecchio S, Menicanti L, Frigiola A, Pelissero G. Risk of assessing mortality risk in elective cardiac operations: age, creatinine, ejection fraction, and the law of parsimony. Circulation 2009;119:3053-61.

8. O'Brien SM, Shahian DM, Filardo G et al. The Society of Thoracic Surgeons 2008 cardiac surgery risk models: part 2--isolated valve surgery. Ann Thorac Surg 2009;88:S23-42.

9. Charlson ME, Pompei P, Ales KL, MacKenzie CR. A new method of classifying prognostic comorbidity in longitudinal studies: development and validation. J Chronic Dis 1987;40:37383.

10. Deyo RA, Cherkin DC, Ciol MA. Adapting a clinical comorbidity index for use with ICD-9CM administrative databases. J Clin Epidemiol 1992;45:613-9. 
11. Fraccaro $\mathrm{P}$, Kontopantelis E, Sperrin $\mathrm{M}$ et al. Predicting mortality from change-over-time in the Charlson Comorbidity Index: A retrospective cohort study in a data-intensive UK health system. Medicine (Baltimore) 2016;95:e4973.

12. Munoz-Garcia AJ, Hernandez-Garcia JM, Jimenez-Navarro MF et al. Survival and predictive factors of mortality after 30 days in patients treated with percutaneous implantation of the CoreValve aortic prosthesis. Am Heart J 2012;163:288-94.

13. Bouleti C, Himbert D, Iung B et al. Long-term outcome after transcatheter aortic valve implantation. Heart 2015;101:936-942.

14. Ludman PF, Group UTS, the National Institute for Cardiovascular Outcomes R. The UK transcatheter aortic valve implantation registry; one of the suite of registries hosted by the National Institute for Cardiovascular Outcomes Research (NICOR). Heart 2012;98:1787-9.

15. Martin GP, Sperrin M, Bagur R et al. Pre-Implantation Balloon Aortic Valvuloplasty and Clinical Outcomes Following Transcatheter Aortic Valve Implantation: A Propensity Score Analysis of the UK Registry. J Am Heart Assoc 2017;6.

16. Charlson ME, Pompei P, Ales KL, MacKenzie CR. A new method of classifying prognostic comorbidity in longitudinal studies: development and validation. Journal of Chronic Diseases $1987 ; 40: 373-383$.

17. Kappetein AP, Head SJ, Genereux P et al. Updated standardized endpoint definitions for transcatheter aortic valve implantation: the Valve Academic Research Consortium-2 consensus document. J Am Coll Cardiol 2012;60:1438-54.

18. Rubin DB. Multiple Imputation for Nonresponse in Surveys. 1987.

19. Sterne JAC, White IR, Carlin JB et al. Multiple imputation for missing data in epidemiological and clinical research: potential and pitfalls. BMJ 2009;338:b2393-b2393. 
20. Jolani S, Debray TP, Koffijberg H, van Buuren S, Moons KG. Imputation of systematically missing predictors in an individual participant data meta-analysis: a generalized approach using MICE. Stat Med 2015;34:1841-63.

21. Nashef SA, Roques F, Sharples LD et al. EuroSCORE II. Eur J Cardiothorac Surg 2012;41:734-44; discussion 744-5.

22. Iung B, Laouenan C, Himbert D et al. Predictive factors of early mortality after transcatheter aortic valve implantation: individual risk assessment using a simple score. Heart 2014;100:1016-23.

23. Stewart GB, Altman DG, Askie LM, Duley L, Simmonds MC, Stewart LA. Statistical analysis of individual participant data meta-analyses: a comparison of methods and recommendations for practice. PLoS One 2012;7:e46042.

24. Burke DL, Ensor J, Riley RD. Meta-analysis using individual participant data: one-stage and two-stage approaches, and why they may differ. Stat Med 2017;36:855-875.

25. Burgess S, White IR, Resche-Rigon M, Wood AM. Combining multiple imputation and meta-analysis with individual participant data. Stat Med 2013;32:4499-514.

26. R Core Team R. R: A Language and Environment for Statistical Computing. Vienna, Austria: R Foundation for Statistical Computing, 2017.

27. Wickham H. ggplot2: elegant graphics for data analysis. 2009.

28. Buuren SV, Groothuis-Oudshoorn K. mice: Multivariate Imputation by Chained Equations in R. Journal of Statistical Software 2011;45:1-67 http://www.jstatsoft.org/v36/i03/.

29. Viechtbauer W. Conducting meta-analyses in $\mathrm{R}$ with the metafor package. Journal of Statistical Software 2010;36:1-48 http://www.jstatsoft.org/v36/i03/. 
30. Kearney L, Ord M, Buxton B et al. Usefulness of the Charlson Co-Morbidity Index to Predict Outcomes in Patients \&gt;60 Years Old With Aortic Stenosis During 18 Years of Follow-Up. The American Journal of Cardiology 2012;110:695-701.

31. Muñoz-García AJ, Hernández-García JM, Jiménez-Navarro MF et al. Survival and predictive factors of mortality after 30 days in patients treated with percutaneous implantation of the CoreValve aortic prosthesis. American Heart Journal 2012;163:288-294.

32. Bagur R, Pibarot P, Otto CM. Importance of the valve durability-life expectancy ratio in selection of a prosthetic aortic valve. Heart 2017;103:1756-1759.

33. Martin GP, Sperrin M, Ludman PF et al. Inadequacy of existing clinical prediction models for predicting mortality after transcatheter aortic valve implantation. Am Heart J 2017;184:97-105.

34. Bagur R, Rodés-Cabau J. Appropriate assessment of operative risk in patients with severe symptomatic aortic stenosis: importance for patient selection in the era of transcatheter aortic valve implantation. Ann Thorac Surg 2011;92:1157-8.

35. Bouleti C, Chauvet M, Franchineau G et al. The impact of the development of transcatheter aortic valve implantation on the management of severe aortic stenosis in high-risk patients: treatment strategies and outcome. Eur J Cardiothorac Surg 2017;51:80-88.

36. Duncan A, Ludman P, Banya W et al. Long-term outcomes after transcatheter aortic valve replacement in high-risk patients with severe aortic stenosis: the U.K. Transcatheter Aortic Valve Implantation Registry. JACC Cardiovasc Interv 2015;8:645-53.

37. Bagur R, Webb JG, Nietlispach F et al. Acute kidney injury following transcatheter aortic valve implantation: predictive factors, prognostic value, and comparison with surgical aortic valve replacement. Eur Heart J 2010;31:865-74. 
38. Thomas M, Schymik G, Walther T et al. One-year outcomes of cohort 1 in the Edwards SAPIEN Aortic Bioprosthesis European Outcome (SOURCE) registry: the European registry of transcatheter aortic valve implantation using the Edwards SAPIEN valve. Circulation $2011 ; 124: 425-33$. 


\section{Tables}

Table 1: Baseline Patient Characteristics and Post-Procedural Outcomes as a Whole Cohort and Across Each Strata of Charlson Comorbidity Index (CCI).

\begin{tabular}{|c|c|c|c|c|c|c|}
\hline Variable & Overall $(n=1887)$ & $\mathrm{CCI}=0(\mathrm{n}=104)$ & $\mathrm{CCI}=1(\mathrm{n}=276)$ & $\mathrm{CCI}=2(n=373)$ & $C C I \geq 3(n=1134)$ & P-value \\
\hline Age, mean (min-max) [missing] & $81.6(23-96)[0]$ & $82.8(43-94)$ & $81.4(23-94)$ & $81.8(51-96)$ & $81.4(44-95)$ & 0.256 \\
\hline Male, $\mathrm{n}(\%)[$ missing] & $970(51.4)[0]$ & $49(47.1)$ & $131(47.5)$ & $165(44.2)$ & $625(55.1)$ & $<0.001$ \\
\hline Diabetic, $\mathrm{n}(\%)$ [missing] & $564(29.9)[2]$ & $8(7.69)$ & $32(11.6)$ & $91(24.4)$ & $433(38.2)$ & $<0.001$ \\
\hline $\begin{array}{l}\text { Current or Ex-smoker, n (\%) } \\
\text { [missing] }\end{array}$ & 750 (39.7) [239] & $34(32.7)$ & $115(41.7)$ & $131(35.1)$ & $470(41.4)$ & 0.063 \\
\hline $\begin{array}{l}\text { Creatinine, mean (min-max) } \\
\text { [missing] }\end{array}$ & $108.6(0-638)[3]$ & $89.6(42-281)$ & $83.6(38-250)$ & $94.3(36-638)$ & $121.2(0-579)$ & $<0.001$ \\
\hline Dialysis, $\mathrm{n}(\%)$ [missing] & $18(0.95)[413]$ & $2(1.92)$ & $0(0)$ & $4(1.07)$ & $12(1.06)$ & 0.275 \\
\hline Previous MI, n (\%) [missing] & $429(22.7)[0]$ & $8(7.69)$ & $42(15.2)$ & $66(17.7)$ & $313(27.6)$ & $<0.001$ \\
\hline $\begin{array}{l}\text { Pulmonary Disease, } \mathrm{n}(\%) \\
\text { [missing] }\end{array}$ & $469(24.9)[5]$ & $7(6.73)$ & $51(18.5)$ & $82(22.0)$ & $329(29.0)$ & $<0.001$ \\
\hline $\begin{array}{l}\text { Neurological Disease, } \mathrm{n}(\%) \\
\text { [missing] }\end{array}$ & $320(17.0)[2]$ & $6(5.77)$ & $39(14.1)$ & $44(11.8)$ & $231(20.4)$ & $<0.001$ \\
\hline $\begin{array}{l}\text { Extracardiac Arteriopathy, n (\%) } \\
\text { [missing] }\end{array}$ & $401(21.3)[2]$ & $12(11.5)$ & $46(16.7)$ & $57(15.3)$ & $286(25.2)$ & $<0.001$ \\
\hline Atrial Fibrillation/Flutter, n (\%) & $549(29.1)[10]$ & $20(19.2)$ & $80(29.0)$ & $98(26.3)$ & $351(31.0)$ & 0.041 \\
\hline
\end{tabular}




\begin{tabular}{|c|c|c|c|c|c|c|}
\hline [missing] & & & & & & \\
\hline $\begin{array}{l}\text { Previous cardiac surgery, } \mathrm{n}(\%) \\
{[\text { missing] }}\end{array}$ & $479(25.4)[0]$ & $32(30.8)$ & $88(31.9)$ & $86(23.1)$ & $273(24.1)$ & 0.020 \\
\hline Previous BAV, $\mathrm{n}(\%)$ [missing] & $322(17.1)[578]$ & $14(13.5)$ & $27(9.78)$ & $69(18.5)$ & $212(18.7)$ & 0.003 \\
\hline Previous PCI, $\mathrm{n}(\%)$ [missing] & $367(19.4)[313]$ & $14(13.5)$ & $37(13.4)$ & $56(15.0)$ & $260(22.9)$ & $<0.001$ \\
\hline $\begin{array}{l}\text { Height-mean (min-max) } \\
\text { [missing] }\end{array}$ & $1.64(1.32-1.90)$ [213] & $1.65(1.38-1.90)$ & $1.64(1.44-1.89)$ & $1.63(1.40-1.90)$ & $1.64(1.32-1.90)$ & 0.033 \\
\hline $\begin{array}{l}\text { Weight, mean (min-max) } \\
\text { [missing] }\end{array}$ & $73.7(40-135.9)[212]$ & $71.7(46-95)$ & $72.6(44-136)$ & $72.1(40-131)$ & $74.7(41-132)$ & 0.009 \\
\hline CCS IV, n (\%) [missing] & $20(1.06)[1017]$ & $0(0)$ & $3(1.09)$ & $5(1.34)$ & $12(1.06)$ & 0.706 \\
\hline NYHA III/IV, n (\%) [missing] & $1546(81.9)[12]$ & $76(73.1)$ & $226(81.9)$ & $289(77.5)$ & $955(84.2)$ & 0.002 \\
\hline $\begin{array}{l}\text { Coronary Artery Disease, } \mathrm{n}(\%) \\
\text { [missing] }\end{array}$ & $960(50.9)[4]$ & $40(38.5)$ & $130(47.1)$ & $170(45.6)$ & $620(54.7)$ & $<0.001$ \\
\hline $\begin{array}{l}\text { Pulmonary Hypertension, } \mathrm{n}(\%) \\
\text { [missing] }\end{array}$ & $265(14.0)[645]$ & $8(7.69)$ & $35(12.7)$ & $50(13.4)$ & $172(15.2)$ & 0.157 \\
\hline $\begin{array}{l}\text { Aortic Valve area, mean (min- } \\
\max )[\text { missing] }\end{array}$ & $0.68(0.20-4.0)[429]$ & $0.68(0.20-2.00)$ & $0.67(0.26-3.71)$ & $0.67(0.20-2.80)$ & $0.69(0.20-4.00)$ & 0.573 \\
\hline LVEF $<50 \%, \mathrm{n}(\%)$ [missing] & $691(36.6)[27]$ & $25(24.0)$ & $93(33.7)$ & $112(30.0)$ & $461(40.7)$ & $<0.001$ \\
\hline $\begin{array}{l}\text { Non-elective procedure, } \mathrm{n}(\%) \\
\text { [missing] }\end{array}$ & $217(11.5)[608]$ & $5(4.81)$ & $32(11.6)$ & $31(8.31)$ & $149(13.1)$ & 0.010 \\
\hline Non-TF Access, n (\%) & $329(17.4)$ & $19(18.3)$ & $41(14.9)$ & $54(14.5)$ & $215(19.0)$ & 0.143 \\
\hline
\end{tabular}




\begin{tabular}{|c|c|c|c|c|c|c|}
\hline $\begin{array}{l}\text { Logistic EuroSCORE, mean \% } \\
(\text { min-max)* }\end{array}$ & $24.8(1.72-98.0)$ & $18.1(4.83-75.6)$ & $22.4(1.72-75.9)$ & $21.4(2.97-73.6)$ & $27.1(2.15-98.0)$ & $<0.001$ \\
\hline STS-Score, mean $\%$ (min-max)* & $5.33(0.59-48.6)$ & $3.70(1.16-19.7)$ & $4.02(0.70-13.7)$ & $4.53(0.88-14.7)$ & $6.05(0.59-48.6)$ & $<0.001$ \\
\hline $\begin{array}{l}\text { EuroSCORE II, mean \% (min- } \\
\text { max)* }\end{array}$ & $8.21(0.78-66.0)$ & $5.94(1.75-25.4)$ & $6.89(0.91-35.9)$ & $6.63(1.03-34.0)$ & $9.26(0.78-66.0)$ & $<0.001$ \\
\hline $\begin{array}{l}\text { FRANCE-2, mean \% (min- } \\
\text { max)* }\end{array}$ & $9.24(3.49-40.6)$ & $7.43(3.49-28.9)$ & $8.20(3.49-27.1)$ & $8.87(3.49-28.9)$ & $9.78(3.49-40.6)$ & $<0.001$ \\
\hline \multicolumn{7}{|l|}{ Outcomes } \\
\hline 30-day mortality, n (\%) & $68 / 1644(4.14 \%)$ & $1 / 94(1.06 \%)$ & $10 / 231(4.33 \%)$ & $11 / 334(3.29 \%)$ & $46 / 985(4.67 \%)$ & 0.312 \\
\hline 1-Year survival, $\%$ & $87.9 \%$ & $95.1 \%$ & $89.3 \%$ & $90.6 \%$ & $85.9 \%$ & $<0.001$ \\
\hline Length of Stay, median (days) & 7 & 8 & 7 & 7 & 8 & 0.018 \\
\hline VARC-2 Early safety, n (\%) & $212 / 1142(18.6 \%)$ & $13 / 69(18.8 \%)$ & $37 / 201(18.4 \%)$ & $26 / 207(12.6 \%)$ & $136 / 665(20.5 \%)$ & 0.089 \\
\hline
\end{tabular}

*The Logistic EuroSCORE, STS-Score and EuroSCORE II each aim to predict short-term mortality following cardiac surgery; the FRANCE-2 model is a TAVI specific model to estimate 30-day mortality risk. All risk models were calculated here using the multiple imputed data. MI: myocardial infarction. BAV: balloon-aortic valvuloplasty. PCI: percutaneous coronary intervention. CCS: Canadian Cardiovascular Society. NYHA: New York Heart Association. LVEF: left ventricular ejection fraction. TF: transfemoral. VARC: Valve Academic Research Consortium. 
Table 2: Differences in 30-day Mortality, Long-term Survival and Length of Stay Per Unit Increases in Total Charlson Comorbidity Index for the whole cohort.

\begin{tabular}{|l|c|}
\hline \multicolumn{1}{|c|}{ 30-day mortality } & OR (95\% CI) \\
\hline Univariable & $1.11(0.98-1.25)$ \\
\hline Age and Sex adjusted & $1.13(1.00-1.27)$ \\
\hline Multivariable* & $1.09(0.96-1.24)$ \\
\hline \multicolumn{1}{|c|}{ VARC-2 Early Safety } & OR (95\% CI) \\
\hline Univariable & $1.08(1.00-1.16)$ \\
\hline Age and Sex adjusted & $1.08(1.00-1.17)$ \\
\hline Multivariable* & $1.04(0.96-1.14)$ \\
\hline \multicolumn{1}{|c|}{ Long-term Survival } & HR (95\% CI) \\
\hline Univariable & $1.11(1.06-1.16)$ \\
\hline Age and Sex adjusted & $1.11(1.06-1.17)$ \\
\hline Multivariable* & $1.10(1.05-1.16)$ \\
\hline \multicolumn{1}{|c|}{ Length of Stay } & HR (95\% CI) \\
\hline Univariable & $0.96(0.94-0.98)$ \\
\hline Age and Sex adjusted & $0.96(0.94-0.98)$ \\
\hline Multivariable* & $1.00(0.97-1.02)$ \\
\hline
\end{tabular}

Each model includes a random intercept at the country-level. *The multivariable model adjusted for the following variables: age, sex, smoking status, atrial fibrillation/flutter, height, weight, Canadian Cardiovascular Society Class IV, New York Heart Association class, coronary artery disease, pulmonary hypertension, aortic valve area, left ventricular ejection fraction, non-elective procedure indication, non-transfemoral access route. CI: confidence interval, OR: odds ratio, HR: hazard ratio. VARC: Valve Academic Research Consortium. 
Table 3: Hazard Ratios for Long-term Survival and Length of Stay, and Odds Ratios for the VARC-2 Composite Early Safety Across Strata of Charlson Comorbidity Index (CCI)

\begin{tabular}{|c|c|c|c|}
\hline Long-term survival & $\begin{array}{c}\text { HR of CCI=1 vs } \\
\text { CCI=0 (95\% CI) }\end{array}$ & $\begin{array}{c}\text { HR of CCI=2 vs } \\
\text { CCI=0 (95\% CI) }\end{array}$ & $\begin{array}{c}\text { HR of CCI } \geq \mathbf{3} \text { vs } \\
\text { CCI=0 (95\% CI) }\end{array}$ \\
\hline Univariable & $1.19(0.68-2.10)$ & $1.80(1.06-3.05)$ & $2.30(1.41-3.76)$ \\
\hline Age and Sex adjusted & $1.21(0.69-2.13)$ & $1.86(1.10-3.16)$ & $2.36(1.44-3.86)$ \\
\hline Multivariable* & $1.17(0.66-2.06)$ & $1.73(1.01-2.94)$ & $2.18(1.32-3.61)$ \\
\hline & HR of CCI=1 vs & HR of CCI=2 vs & HR of CCI $\geq 3$ vs \\
\hline Length of stay & CCI=0 (95\% CI) & CCI=0 (95\% CI) & CCI=0 (95\% CI) \\
\hline Univariable & $1.13(0.89-1.43)$ & $1.17(0.93-1.47)$ & $0.96(0.77-1.18)$ \\
\hline Age and Sex adjusted & $1.12(0.89-1.43)$ & $1.17(0.93-1.47)$ & $0.95(0.77-1.18)$ \\
\hline Multivariable* & $1.31(1.02-1.67)$ & $1.41(1.11-1.79)$ & $1.27(1.02-1.59)$ \\
\hline VARC-2 Early Safety & OR of CCI=1 vs & OR of CCI=2 vs & OR of CCI $\geq 3$ vs \\
\hline Univariable & $0.98(0.48-1.98)$ & $0.63(0.30-1.32)$ & $1.14(0.60-2.15)$ \\
\hline Age and Sex adjusted & $0.99(0.49-2.00)$ & $0.64(0.31-1.34)$ & $1.16(0.61-2.20)$ \\
\hline Multivariable* & $0.94(0.45-1.94)$ & $0.57(0.27-1.21)$ & $0.94(0.48-1.85)$ \\
\hline
\end{tabular}

Patients with $\mathrm{CCI}=0$ were used as the reference group. Each model includes a random intercept at the country-level. *The multivariable model adjusted for the following variables: age, sex, smoking status, atrial fibrillation/flutter, height, weight, Canadian Cardiovascular Society Class IV, New York Heart Association Class, coronary artery disease, pulmonary hypertension, aortic valve area, left ventricular ejection fraction, non-elective procedure indication, non-transfemoral access route. CI: confidence interval, OR: odds ratio, HR: hazard ratio, VARC: Valve Academic Research Consortium. 
Figures legends

Figure 1: Distribution of total Charlson Comorbidity Index (CCI) as a Whole Cohort and by Country. UK: United Kingdom.

Figure 2: Proportion of Patients Within Each Charlson Comorbidity Index (CCI) Strata Across Quantile of Predicted Risk Models. LES: logistic EuroSCORE, ESII: EuroSCORE-II, STS: Society of Thoracic Surgeons.

Figure 3: Kaplan-Meier for Long-term Survival by Charlson Comorbidity Index (CCI) strata. TAVI: transcatheter aortic valve implantation.

Figure 4: Forest Plot of (multivariable adjusted) Hazard Ratios for Long-term Survival (top panel) and Length of Stay (bottom panel). Data from a two-stage individual participant data random-effect meta-analysis. UK: United Kingdom. CCI: Charlson Comorbidity Index.

Figure 5. Multivariable adjusted hazard ratio for shorter length of stay as a smooth function of total Charlson Comorbidity Index (CCI). 

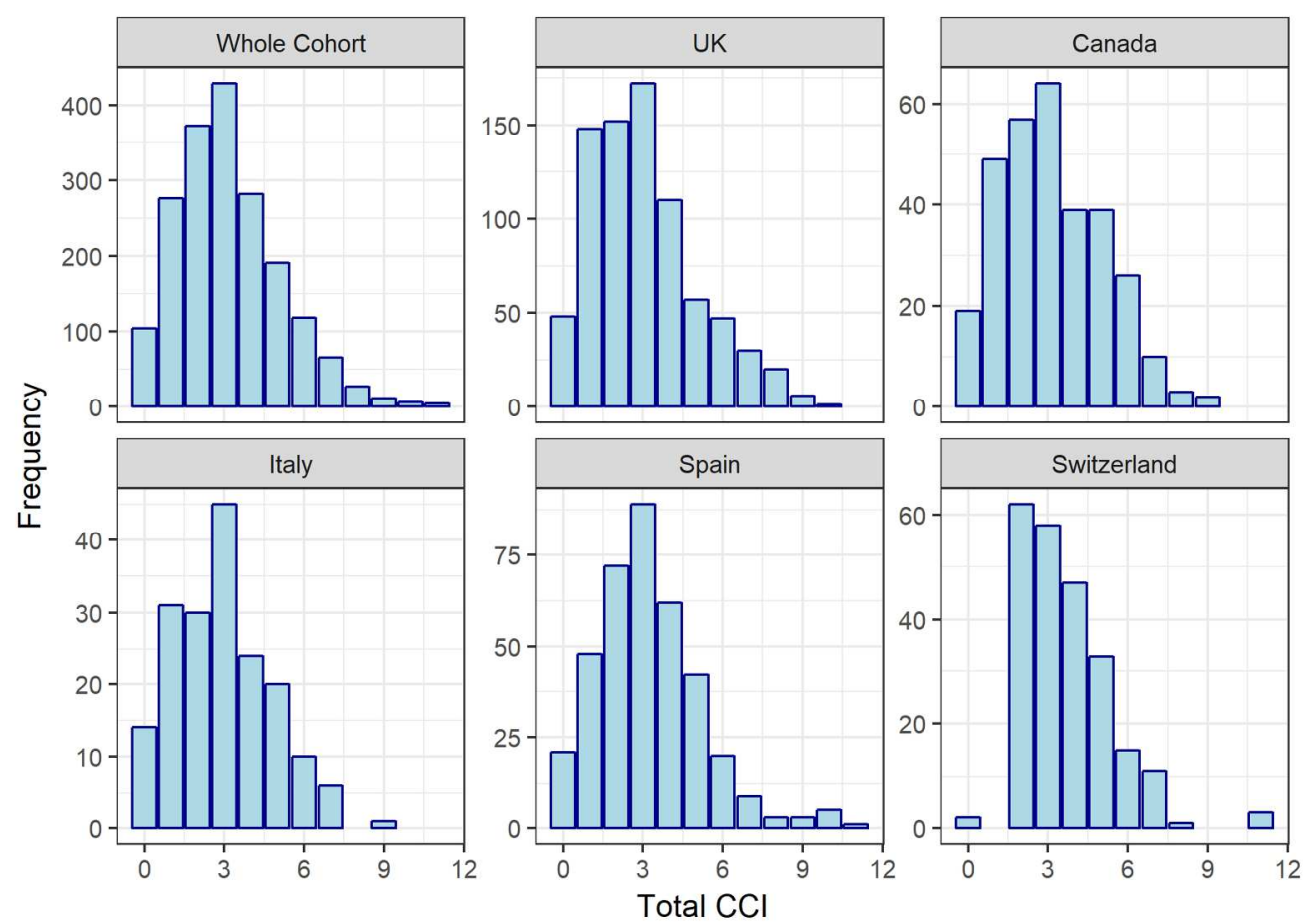

Figure 1

$177 \times 127 \mathrm{~mm}(300 \times 300$ DPI) 
Total CCI Strata $\begin{array}{llllll}0 & 1 & 2 & 3+\end{array}$

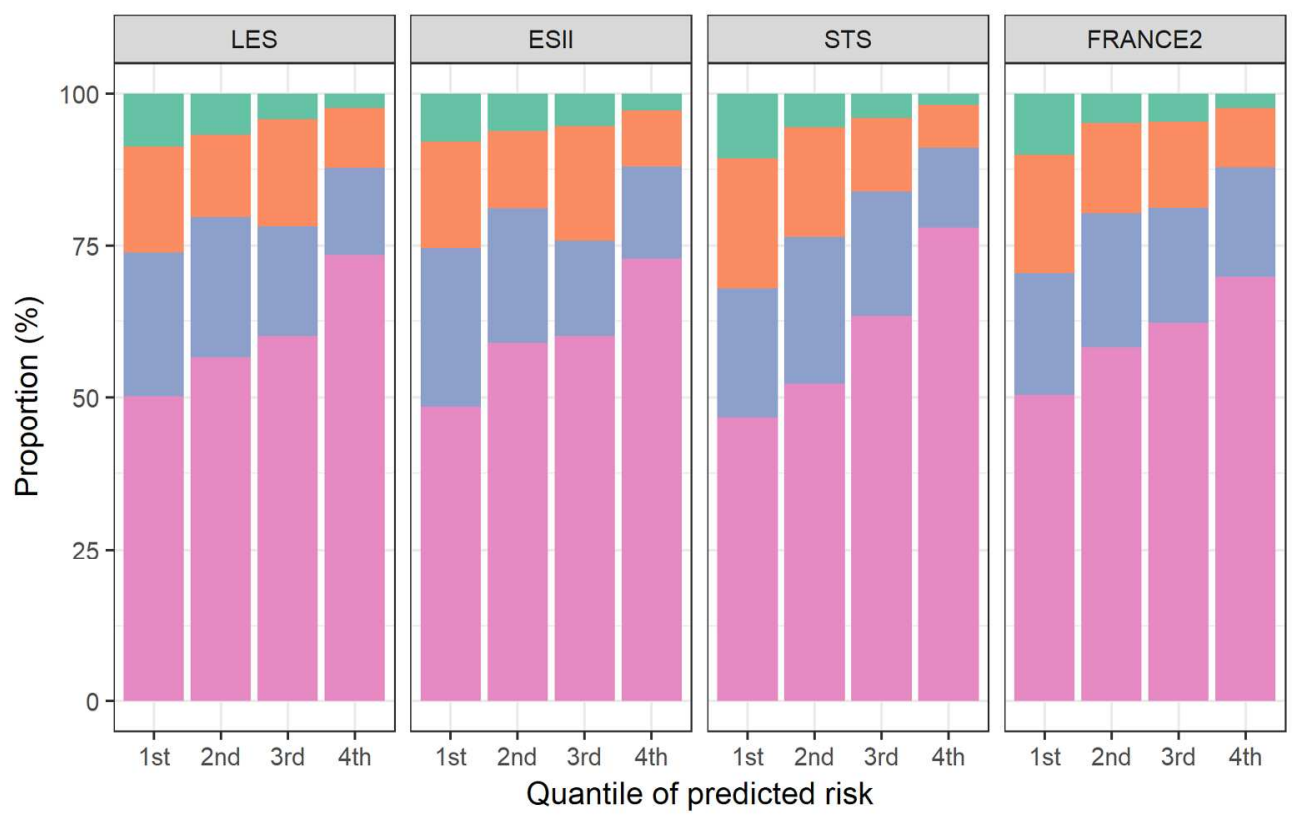

Figure 2

$177 \times 127 \mathrm{~mm}(300 \times 300$ DPI $)$ 

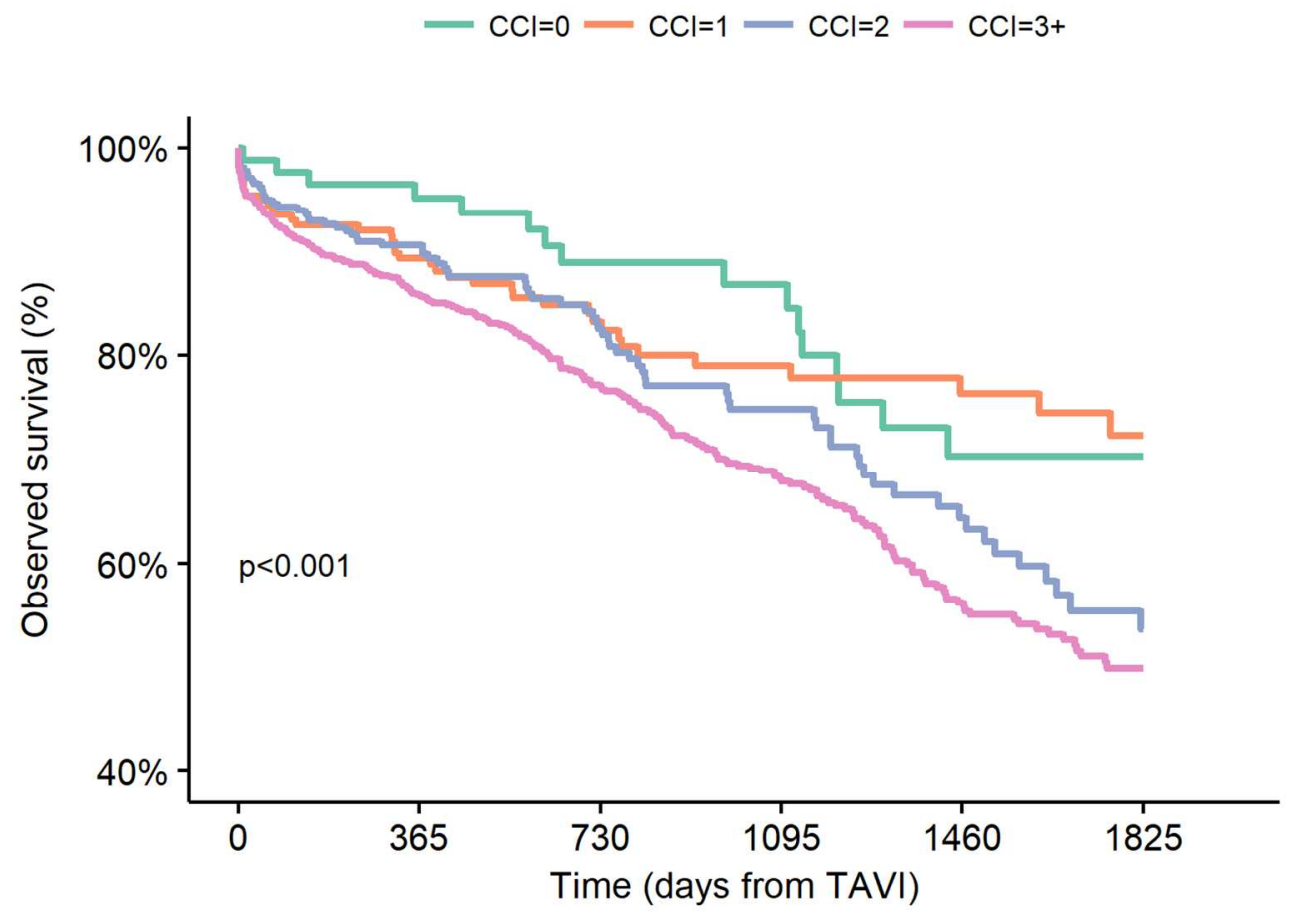

Number at risk

$\begin{array}{cccccc}86 & 69 & 51 & 38 & 26 & 17 \\ 219 & 156 & 104 & 70 & 49 & 31 \\ 319 & 246 & 141 & 88 & 58 & 30 \\ 931 & 701 & 420 & 261 & 144 & 82\end{array}$

Figure 3

$127 \times 127 \mathrm{~mm}(300 \times 300$ DPI $)$ 


\section{Long-term Survival}

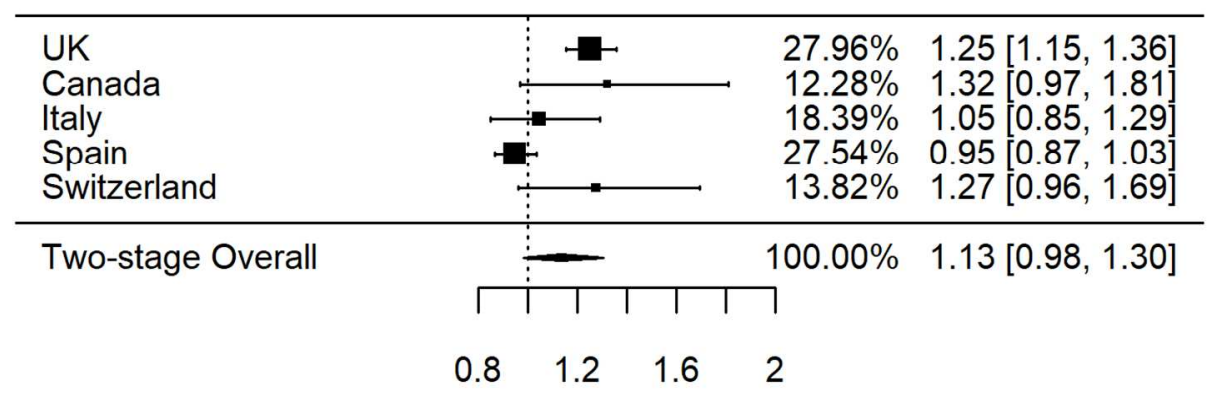

Hazard Ratio for $\mathrm{CCl}$ Total

\section{Length of Stay}

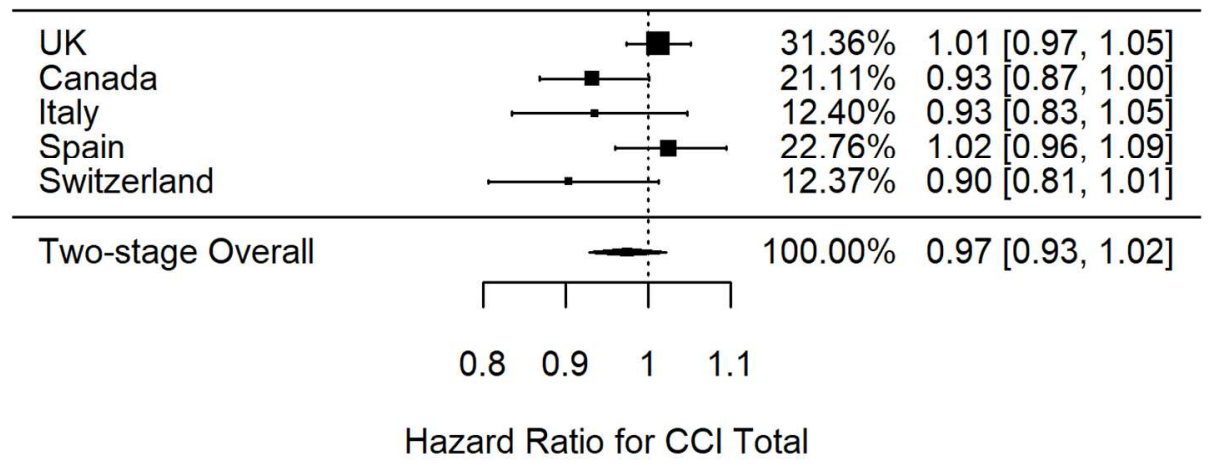

Figure 4

$127 \times 152 \mathrm{~mm}(300 \times 300$ DPI $)$ 


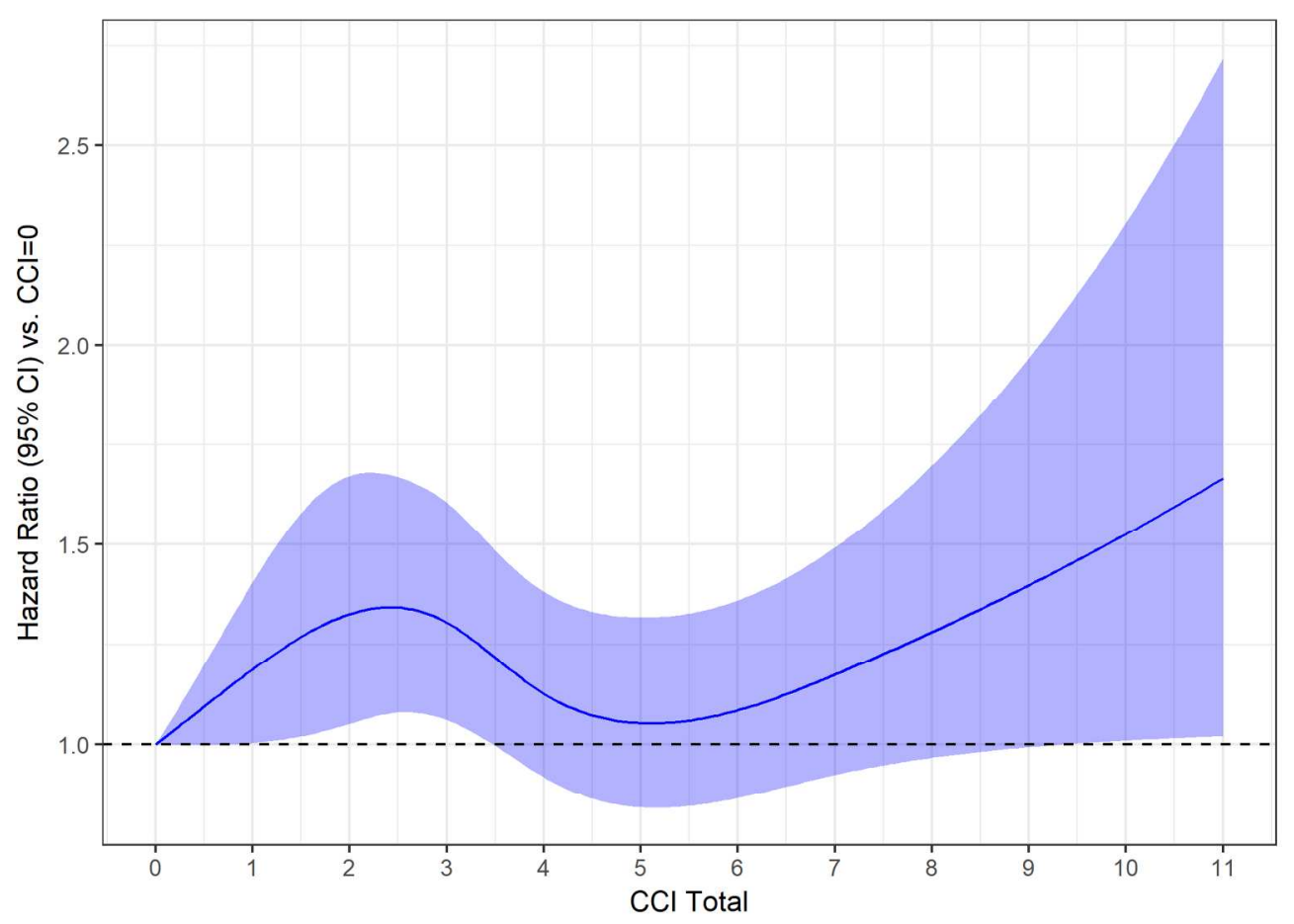

Figure 5

$177 \times 127 \mathrm{~mm}(300 \times 300 \mathrm{DPI})$ 


\section{SUPPLEMENTARY MATERIAL}

Supplementary Figure 1: Proportion of Patients Within Each Charlson Comorbidity Index (CCI) Strata Across Country.

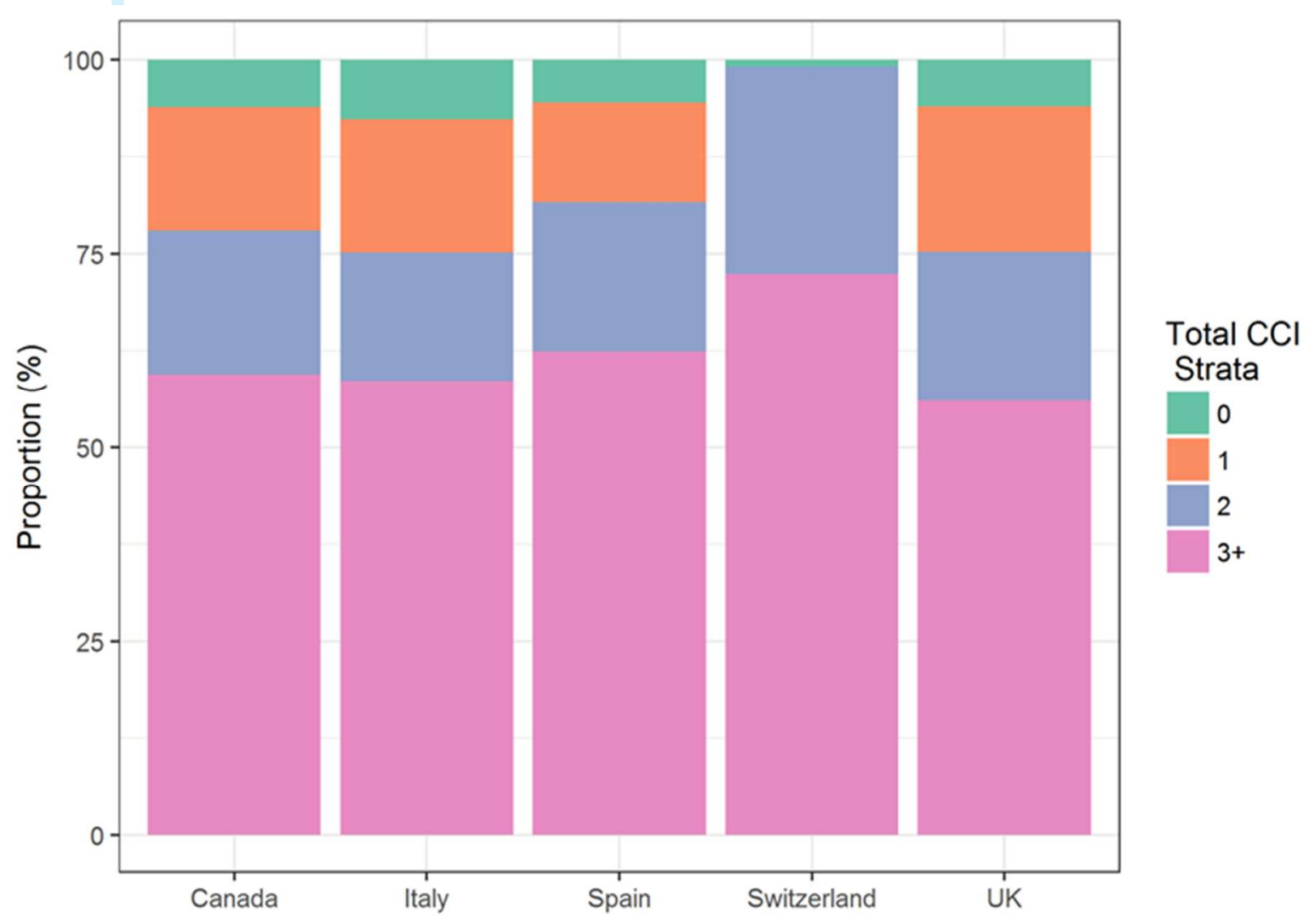


Supplementary Figure 2: Prevalence of each Charlson Comorbidity Index (CCI) component.

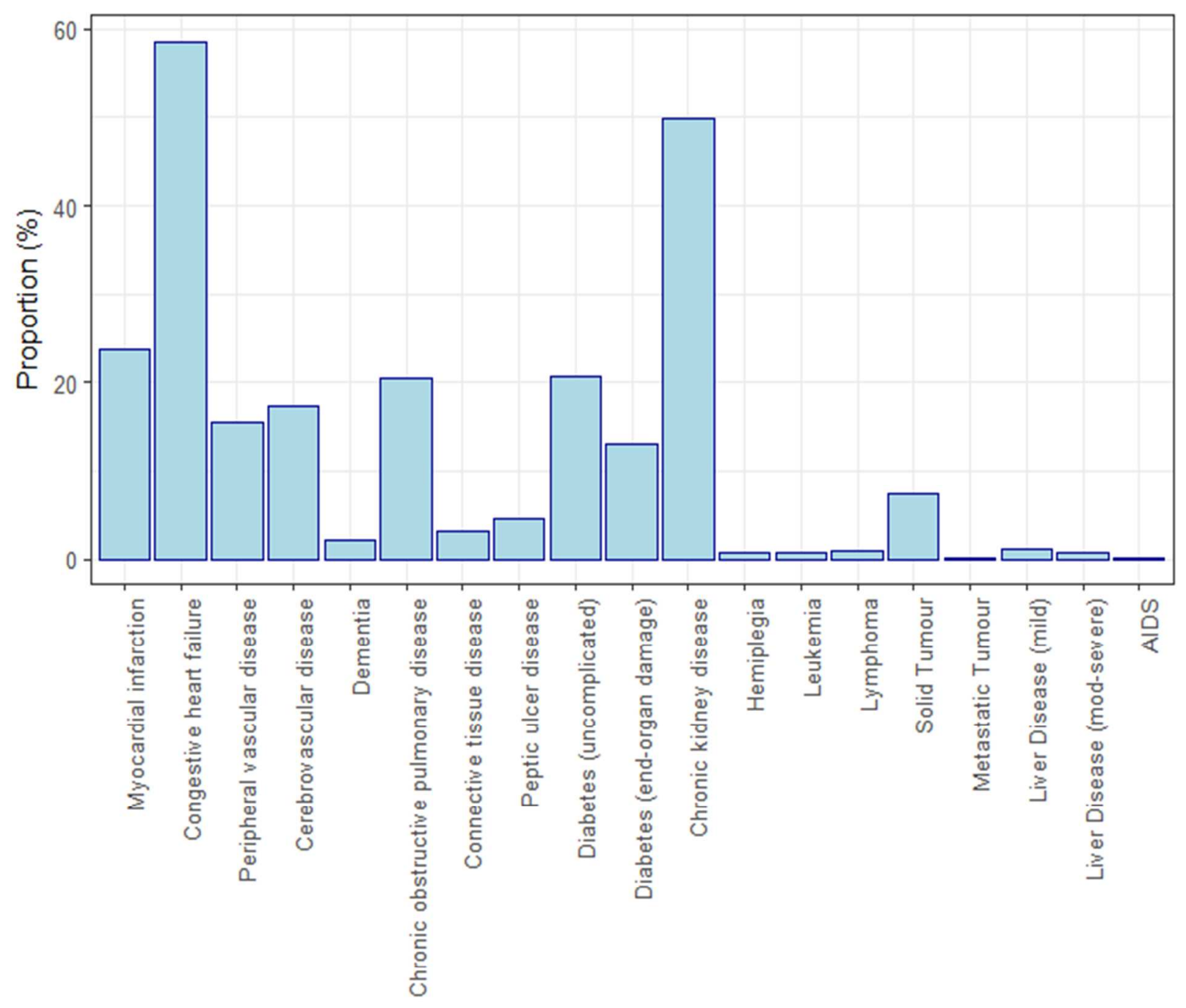


Supplementary Figure 3: Forest plot of odds ratios for 30-day mortality from a two-stage individual participant data meta-analysis; estimates adjusted for the following variables: age, sex, smoking status, atrial fibrillation/flutter, height, weight, Canadian Cardiovascular Society Class IV, New York Heart Association, coronary artery disease, and aortic valve area. Charlson Comorbidity Index (CCI). UK: United Kingdom.

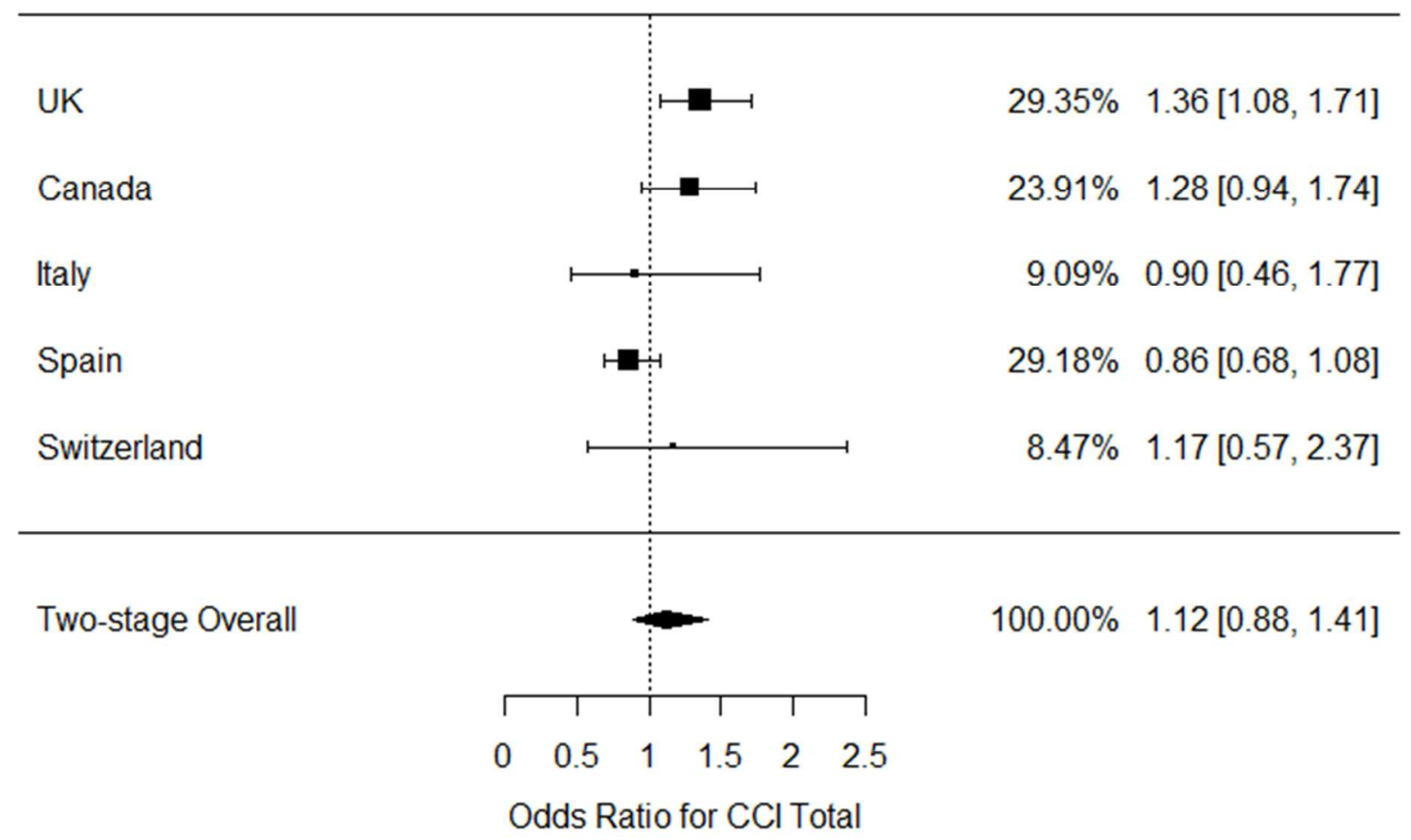


Supplementary Figure 4: Forest plot of (multivariable adjusted) hazard ratios (HRs) for length of stay from a two-stage individual participant data random-effect meta-analysis across strata of total Charleston Comorbidity Index (CCI). UK: United Kingdom.
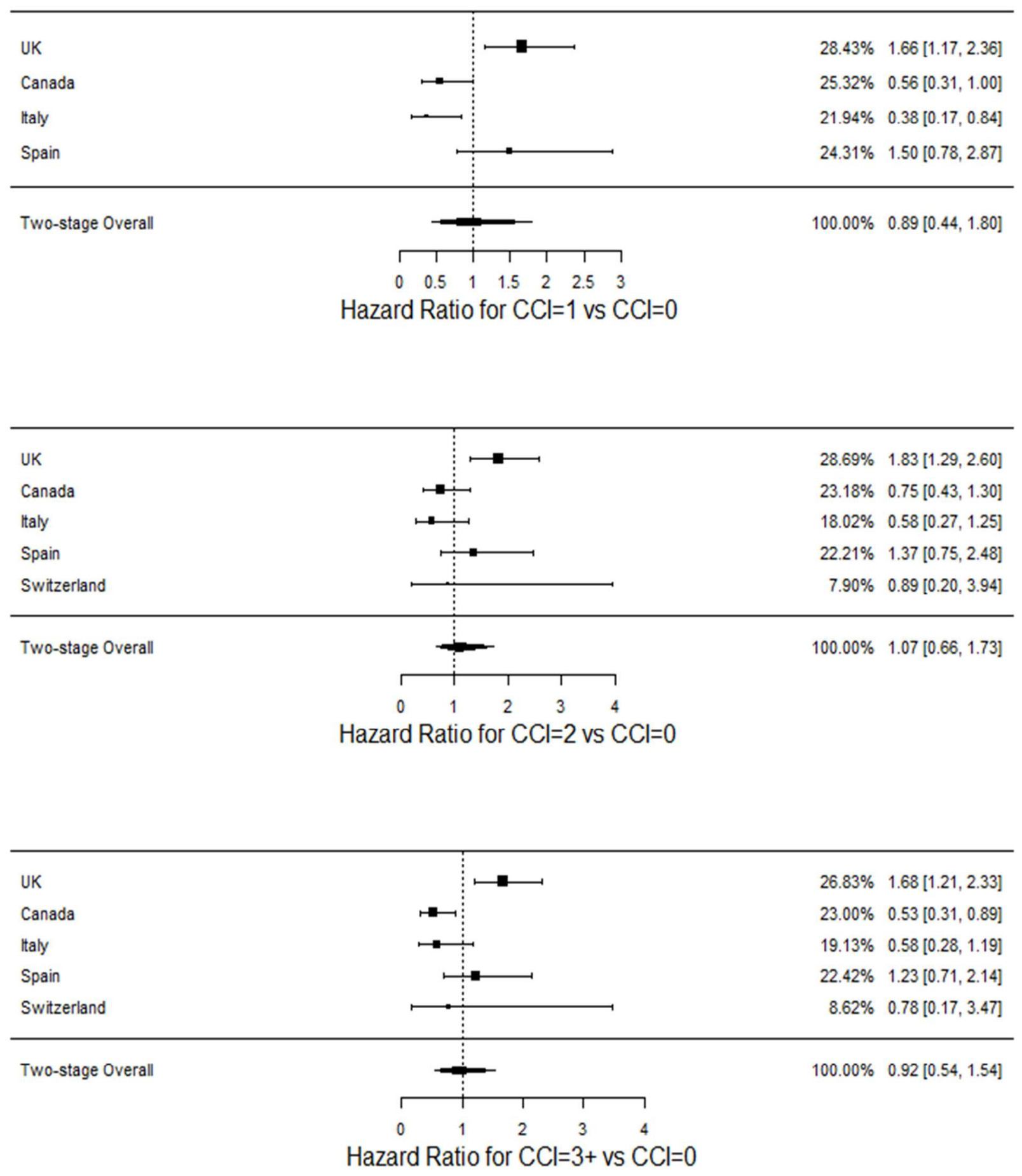
Supplementary Table 1: Baseline patient characteristics across each country of data origin.

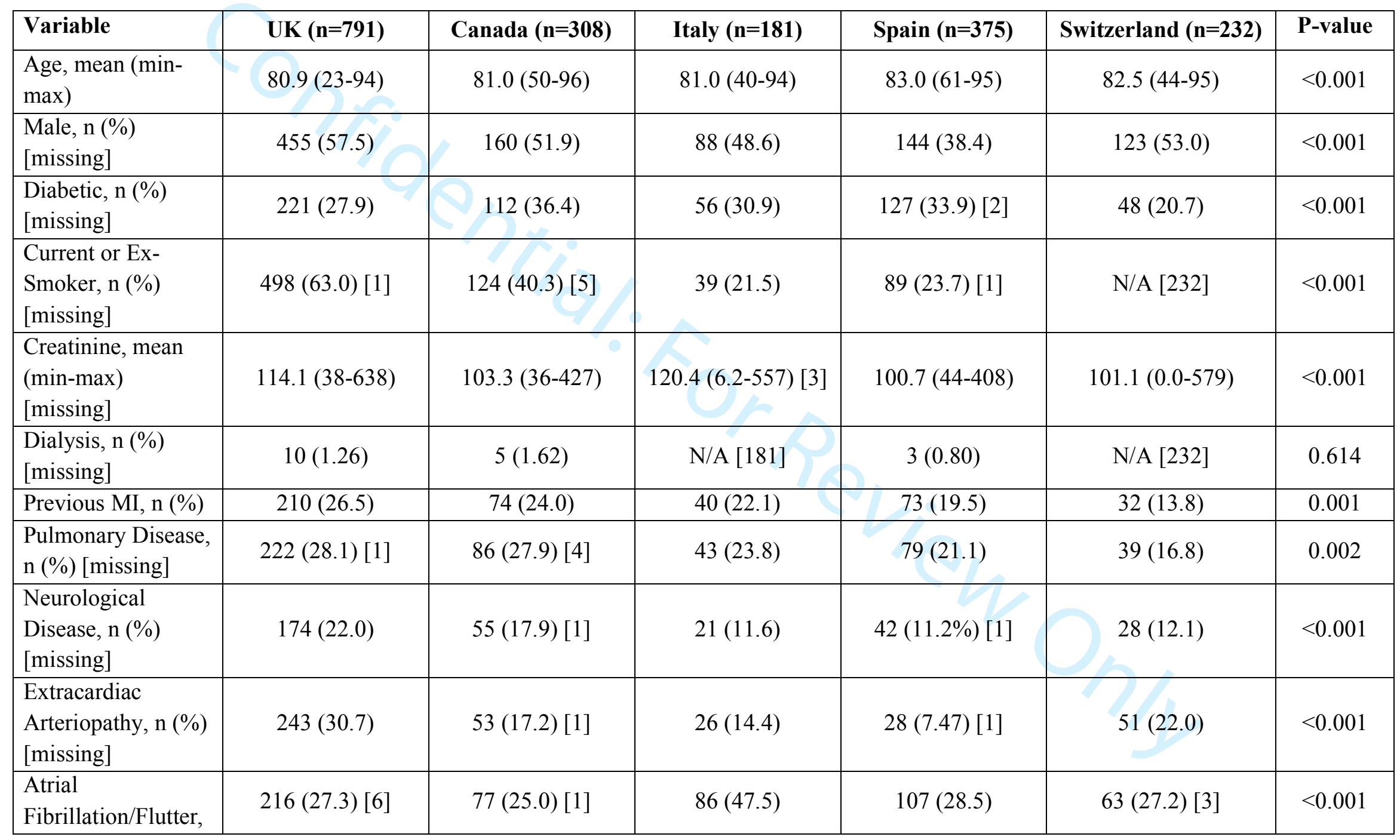




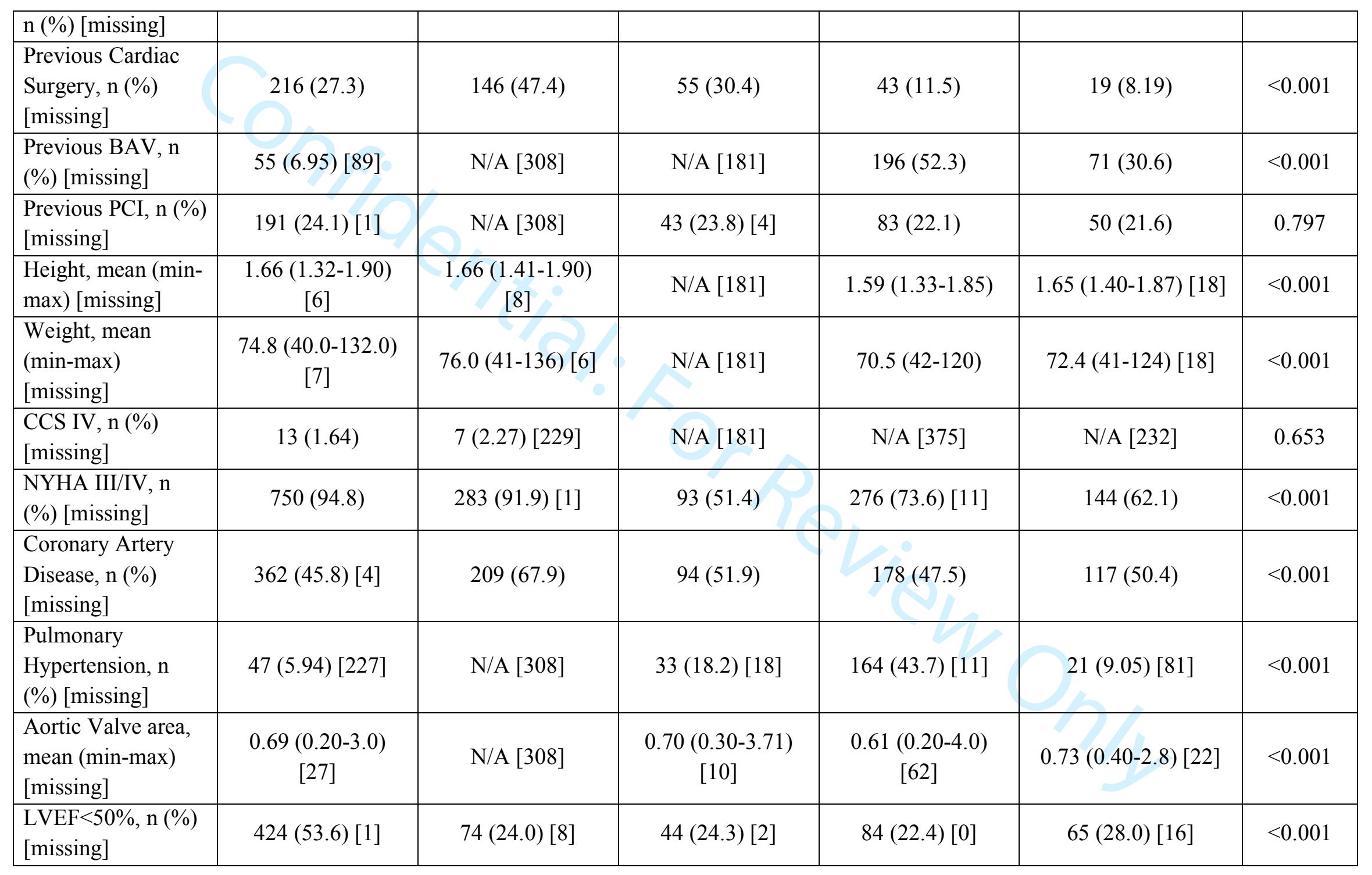




\begin{tabular}{|c|c|c|c|c|c|c|}
\hline $\begin{array}{l}\text { Non-elective } \\
\text { procedure, } \mathrm{n}(\%) \\
\text { [missing] }\end{array}$ & $176(22.3)[1]$ & $37(12.0)$ & $4(2.21)$ & N/A [375] & N/A [232] & $<0.001$ \\
\hline $\begin{array}{l}\text { Non-TF Access, } \mathrm{n} \\
(\%)[\text { missing] }\end{array}$ & $111(14.0)$ & $129(41.9)$ & $54(29.8)$ & $0(0)$ & $35(15.1)$ & $<0.001$ \\
\hline $\begin{array}{l}\text { Logistic } \\
\text { EuroSCORE, mean } \\
\%(\min -\max )^{*}\end{array}$ & $27.4(2.2-98)$ & $26.6(2.8-87.4)$ & $22.9(2.01-79.5)$ & $22.3(1.72-83.4)$ & $19.3(3.25-69.5)$ & $<0.001$ \\
\hline $\begin{array}{l}\text { EuroSCORE II, } \\
\text { mean \% (min- } \\
\max )^{*}\end{array}$ & $10.1(0.78-66.0)$ & $9.12(1.21-49.3)$ & $7.21(0.91-41.3)$ & $5.69(0.96-38.9)$ & $5.59(1.02-29.5)$ & $<0.001$ \\
\hline $\begin{array}{l}\text { FRANCE- } 2, \text { mean } \\
\%(\text { min-max })^{*}\end{array}$ & $9.29(3.49-40.6)$ & $10.0(3.49-32.8)$ & $9.83(4.16-33.7)$ & $7.19(3.49-28.9)$ & $10.9(3.49-34.1)$ & $<0.001$ \\
\hline 1-Year survival, $\%$ & 86.3 & 94.8 & 75.1 & 82.0 & 95.7 & $<0.001$ \\
\hline $\begin{array}{l}\text { Length of Stay, } \\
\text { median (days) }\end{array}$ & 7 & 6 & 13 & 7 & 7 & $<0.001$ \\
\hline $\begin{array}{l}\text { VARC-2 Early } \\
\text { safety, n (\%) }\end{array}$ & $134 / 661(20.3)$ & $32 / 300(10.7)$ & 46/181 (25.4) & N/A & N/A & $<0.001$ \\
\hline
\end{tabular}

Cells denoted with "N/A" indicate 100\% missing data for that particular country/variable combination. *The Logistic EuroSCORE, STS-Score and EuroSCORE II each aim to predict short-term mortality following cardiac surgery; the FRANCE-2 model is a TAVI specific model to estimate 30-day mortality risk. All risk models were calculated here using the multiple imputed data. UK: United Kingdom. MI: myocardial infarction. BAV: balloon-aortic 
valvuloplasty. PCI: percutaneous coronary intervention. CCS: Canadian Cardiovascular Society. NYHA: New York Heart Association. LVEF: left ventricular ejection fraction. TF: transfemoral. VARC: Valve Academic Research Consortium. 


\section{STROBE Statement - Checklist of items that should be included in reports of observational studies}

\begin{tabular}{|c|c|c|c|}
\hline & $\begin{array}{c}\text { Item } \\
\text { No }\end{array}$ & Checklist of item & Reported on page \# \\
\hline \multirow{2}{*}{ Title and abstract } & \multirow{2}{*}{1} & (a) Indicate the study's design with a commonly used term in the title or the abstract & 1 and 2 \\
\hline & & (b) Provide in the abstract an informative and balanced summary of what was done and what was found & 1 and 2 \\
\hline \multicolumn{4}{|l|}{ Introduction } \\
\hline Background/rationale & 2 & Explain the scientific background and rationale for the investigation being reported & 5 \\
\hline Objectives & 3 & State specific objectives, including any pre-specified hypotheses & 5 \\
\hline \multicolumn{4}{|l|}{ Methods } \\
\hline Study design & 4 & Present key elements of study design early in the paper & 5 and 6 \\
\hline Setting & 5 & Describe the setting, locations, and relevant dates, including periods of recruitment, exposure, follow-up, and data collection & 5 and 5 \\
\hline Participants & 6 & $\begin{array}{l}\text { (a) Cohort study - Give the eligibility criteria, and the sources and methods of selection of participants. Describe methods of } \\
\text { follow-up } \\
\text { Case-control study - Give the eligibility criteria, and the sources and methods of case ascertainment and control selection. } \\
\text { Give the rationale for the choice of cases and controls } \\
\text { Cross-sectional study - Give the eligibility criteria, and the sources and methods of selection of participants }\end{array}$ & 5 and 6 \\
\hline Variables & 7 & $\begin{array}{l}\text { Clearly define all outcomes, exposures, predictors, potential confounders, and effect modifiers. Give diagnostic criteria, if } \\
\text { applicable }\end{array}$ & 7 \\
\hline $\begin{array}{l}\text { Data sources/ } \\
\text { measurement }\end{array}$ & $8^{*}$ & $\begin{array}{l}\text { For each variable of interest, give sources of data and details of methods of assessment (measurement). Describe } \\
\text { comparability of assessment methods if there is more than one group }\end{array}$ & 7 and 8 \\
\hline Bias & 9 & Describe any efforts to address potential sources of bias & 8 \\
\hline Study size & 10 & Explain how the study size was arrived at & 5 and 6 \\
\hline Quantitative variables & 11 & $\begin{array}{l}\text { Explain how quantitative variables were handled in the analyses. If applicable, describe which groupings were chosen and } \\
\text { why }\end{array}$ & 6 to 8 \\
\hline \multirow{3}{*}{ Statistical methods } & \multirow{3}{*}{12} & (a) Describe all statistical methods, including those used to control for confounding & 6 to 8 \\
\hline & & (b) Describe any methods used to examine subgroups and interactions & 6 to 8 \\
\hline & & (c) Explain how missing data were addressed & 6 to 8 \\
\hline
\end{tabular}




\begin{tabular}{|c|c|c|c|}
\hline \multicolumn{3}{|l|}{ Results } & \\
\hline \multirow{3}{*}{ Participants } & \multirow{3}{*}{$13^{*}$} & $\begin{array}{l}\text { (a) Report numbers of individuals at each stage of study—eg numbers potentially eligible, examined for eligibility, confirmed eligible, } \\
\text { included in the study, completing follow-up, and analysed }\end{array}$ & 9 \\
\hline & & (b) Give reasons for non-participation at each stage & Not Applicable \\
\hline & & (c) Consider use of a flow diagram & Not Applicable \\
\hline \multirow{3}{*}{$\begin{array}{l}\text { Descriptive } \\
\text { data }\end{array}$} & \multirow{3}{*}{$14^{*}$} & $\begin{array}{l}\text { (a) Give characteristics of study participants (eg demographic, clinical, social) and information on exposures and potential } \\
\text { confounders }\end{array}$ & 9 \\
\hline & & (b) Indicate number of participants with missing data for each variable of interest & $\begin{array}{l}\text { Table } 1 \text { and } \\
\text { Supplementary Table } 1\end{array}$ \\
\hline & & (c) Cohort study-Summarise follow-up time (eg, average and total amount) & 10 \\
\hline Outcome data & $15^{*}$ & Cohort study-Report numbers of outcome events or summary measures over time & 9 to 12 \\
\hline \multirow{3}{*}{ Main results } & \multirow{3}{*}{16} & $\begin{array}{l}\text { (a) Give unadjusted estimates and, if applicable, confounder-adjusted estimates and their precision (eg, 95\% confidence interval). } \\
\text { Make clear which confounders were adjusted for and why they were included }\end{array}$ & 10 and 11 \\
\hline & & (b) Report category boundaries when continuous variables were categorized & 9 to 11 \\
\hline & & (c) If relevant, consider translating estimates of relative risk into absolute risk for a meaningful time period & As Hazzard Ratio \\
\hline Other analyses & 17 & Report other analyses done-eg analyses of subgroups and interactions, and sensitivity analyses & Not Applicable \\
\hline \multicolumn{4}{|l|}{ Discussion } \\
\hline Key results & 18 & Summarise key results with reference to study objectives & 12 \\
\hline Limitations & 19 & $\begin{array}{l}\text { Discuss limitations of the study, taking into account sources of potential bias or imprecision. Discuss both direction and magnitude of } \\
\text { any potential bias }\end{array}$ & 14 \\
\hline Interpretation & 20 & $\begin{array}{l}\text { Give a cautious overall interpretation of results considering objectives, limitations, multiplicity of analyses, results from similar } \\
\text { studies, and other relevant evidence }\end{array}$ & 15 \\
\hline Generalisability & 21 & Discuss the generalisability (external validity) of the study results & 13 and 14 \\
\hline \multicolumn{4}{|c|}{ Other information } \\
\hline Funding & 22 & $\begin{array}{l}\text { Give the source of funding and the role of the funders for the present study and, if applicable, for the original study on which the } \\
\text { present article is based }\end{array}$ & 1 \\
\hline
\end{tabular}

*Give information separately for cases and controls in case-control studies and, if applicable, for exposed and unexposed groups in cohort and cross-sectional studies.

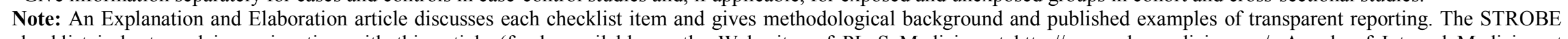

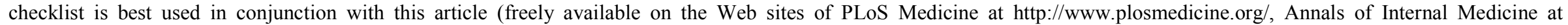
http://www.annals.org/, and Epidemiology at http://www.epidem.com/). Information on the STROBE Initiative is available at www.strobe-statement.org. 